\title{
On breaks of the Indian monsoon
}

\author{
Sulochana Gadgil ${ }^{1}$ and P V Joseph ${ }^{2}$ \\ ${ }^{1}$ Centre for Atmospheric and Oceanic Sciences and Centre for Ecological Sciences, Indian Institute of Science, \\ Bangalore 560 012, India. \\ ${ }^{2}$ Department of Atmospheric Sciences, Cochin University of Science and Technology, Cochin 682 016, India.
}

For over a century, the term break has been used for spells in which the rainfall over the Indian monsoon zone is interrupted. The phenomenon of 'break monsoon' is of great interest because long intense breaks are often associated with poor monsoon seasons. Such breaks have distinct circulation characteristics (heat trough type circulation) and have a large impact on rainfed agriculture. Although interruption of the monsoon rainfall is considered to be the most important feature of the break monsoon, traditionally breaks have been identified on the basis of the surface pressure and wind patterns over the Indian region. We have defined breaks (and active spells) on the basis of rainfall over the monsoon zone. The rainfall criteria are chosen so as to ensure a large overlap with the traditional breaks documented by Ramamurthy (1969) and De et al (1998). We have identified these rainbreaks for 1901-89. We have also identified active spells on the basis of rainfall over the Indian monsoon zone. We have shown that the all-India summer monsoon rainfall is significantly negatively correlated with the number of rainbreak days (correlation coefficient -0.56) and significantly positively correlated with the number of active days (correlation coefficient 0.47 ). Thus the interannual variation of the all-India summer monsoon rainfall is shown to be related to the number of days of rainbreaks and active spells identified here.

There have been several studies of breaks (and also active spells in several cases) identified on the basis of different criteria over regions differing in spatial scales (e.g., Webster et al 1998; Krishnan et al 2000; Goswami and Mohan 2000; and Annamalai and Slingo 2001). We find that there is considerable overlap between the rainbreaks we have identified and breaks based on the traditional definition. There is some overlap with the breaks identified by Krishnan et al (2000) but little overlap with breaks identified by Webster et al (1998). Further, there are three or four active-break cycles in a season according to Webster et al (1998) which implies a time scale of about 40 days for which Goswami and Mohan (2000), and Annamalai and Slingo (2001) have studied breaks and active minus break fluctuations. On the other hand, neither the traditional breaks (Ramamurthy 1969; and De et al 1998) nor the rainbreaks occur every year. This suggests that the 'breaks' in these studies are weak spells of the intraseasonal variation of the monsoon, which occur every year.

We have derived the OLR and circulation patterns associated with rainbreaks and active spells and compared them with the patterns associated with breaks/active minus break spells from these studies. Inspite of differences in the patterns over the Indian region, there is one feature which is seen in the OLR anomaly patterns of breaks identified on the basis of different criteria as well as the rainbreaks identified in this paper viz., a quadrapole over the Asia-west Pacific region arising from anomalies opposite (same) in sign to those over the Indian region occurring over the equatorial Indian Ocean and northern tropical (equatorial) parts of the west Pacific. Thus it appears that this quadrapole is a basic feature of weak spells of the intraseasonal variation over the Asia-west Pacific region. Since the rainbreaks are intense weak spells, this basic feature is also seen in the composite patterns of these breaks. We find that rainbreaks (active spells) are also associated with negative

Keywords. Indian monsoon; intraseasonal variation; active and weak spells; monsoon breaks.

Proc. Indian Acad. Sci. (Earth Planet. Sci.), 112, No. 4, December 2003, pp. 529-558

(C) Printed in India. 
(positive) anomalies over a part of the east Pacific suggesting that the convection over the Indian region is linked to that over the east Pacific not only on the interannual scale (as evinced by the link between the Indian summer monsoon rainfall and ENSO) but on the intraseasonal scale as well.

\section{Introduction}

Large intraseasonal fluctuations in the Indian monsoon rainfall between active spells and breaks have been known since over a century. Blanford (1886) first described this fluctuation in the rainfall over the monsoon trough zone between spells 'during the height of rains' and 'intervals of drought', and elucidated the nature of the pressure distribution and circulation associated with these phases of contrasting rainfall conditions. In his words "The normal meeting place of the eastern and western branches of the monsoon is indicated by the trough of low pressure, which runs down from the Punjab to the southeast; the westerly branch prevailing to the southwest of this trough, and the easterly branch (more frequently in the Gangetic plain) to the northeast (as in figure 1 for mean July surface pressure \& winds after Rao 1976). In intervals of drought, when northwesterly and westerly winds interrupt the monsoon in North-Western and Central India, it (the trough of low pressure) is pushed northward to the foot of the hills. On the other hand, during the height of the rains, at certain intervals, true cyclonic vortices, with closed isobars (barometric minima) are formed on or in the immediate neighbourhood of this trough".

The summer monsoon season extends from the onset of the monsoon in May/June to its retreat in September. The monsoon trough or the tropical convergence zone (TCZ) is established near the mean seasonal location over the Indian subcontinent at the culmination of the onset phase in July. The mean rainfall during the peak monsoon months of July and August is shown in figure 2. The large-scale monsoon rainfall occurs in the

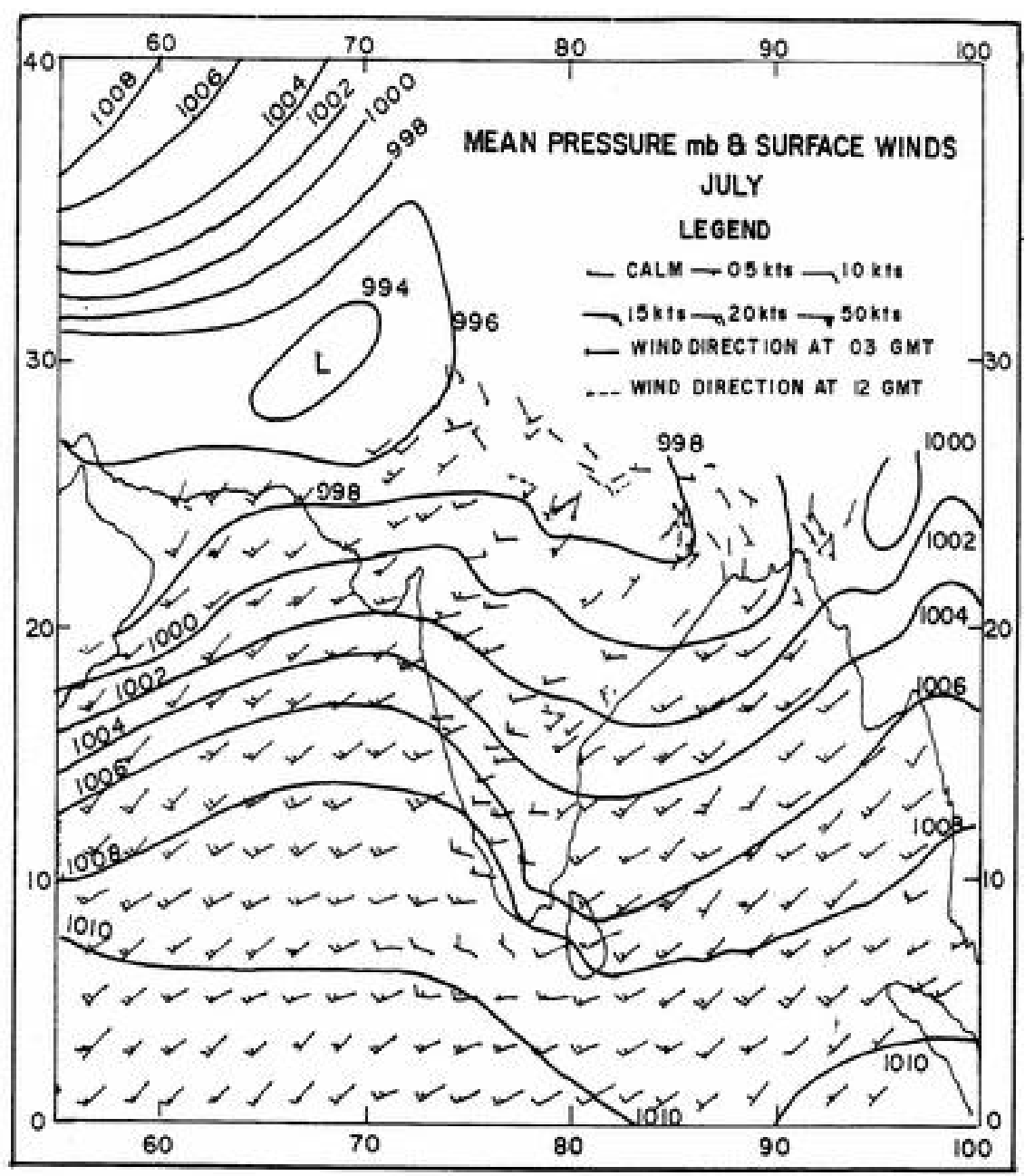

Figure 1. Mean pressure and surface winds for July. 


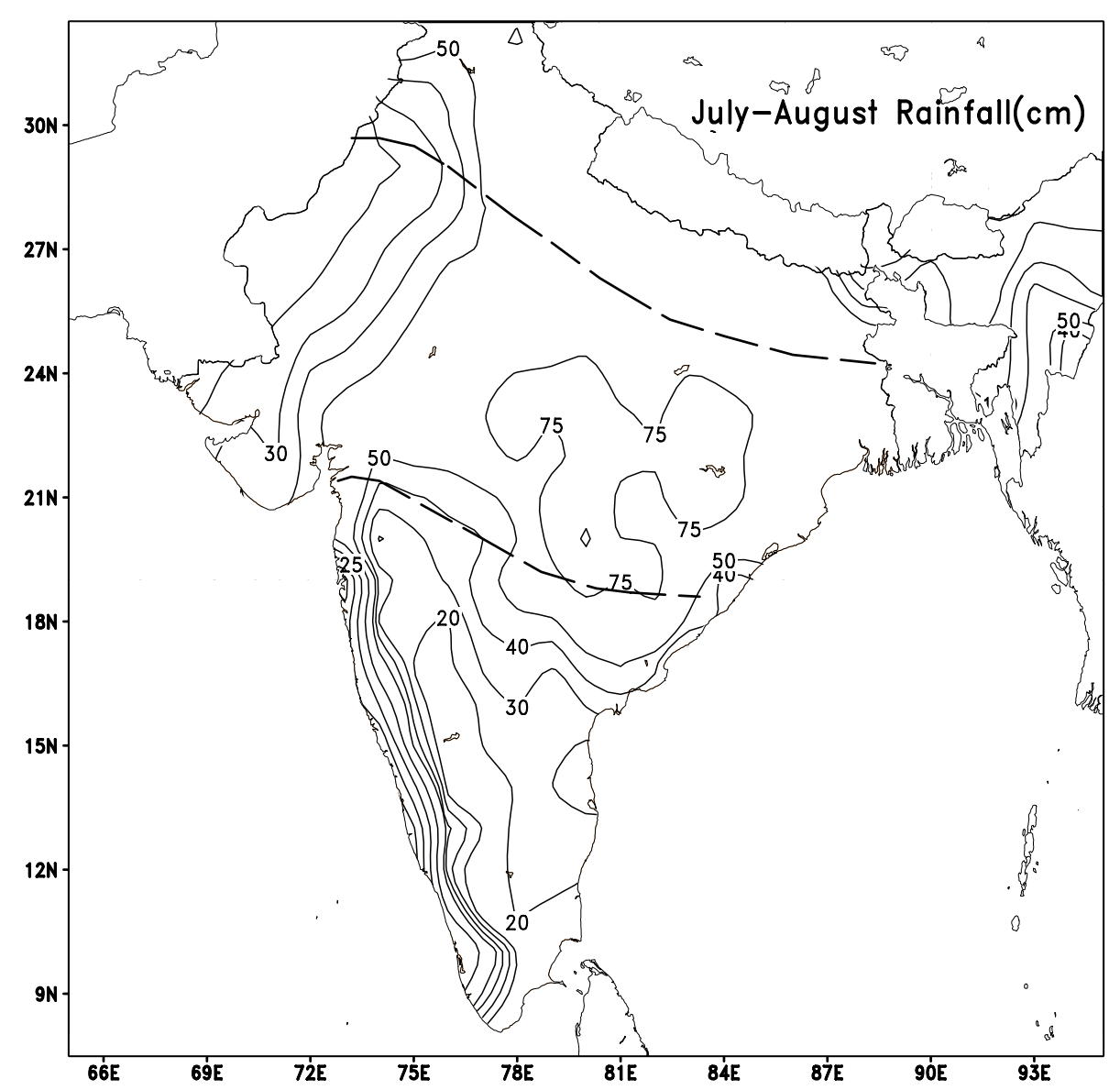

Figure 2. Mean rainfall during July-August. The monsoon zone is the region within the dashed lines.

so-called monsoon zone, within which the continental TCZ fluctuates (Sikka and Gadgil 1980 and references therein). Note that, in addition, copious rainfall occurs over the west coast of the peninsula and northeastern parts of India. The "intervals of drought" noted by Blanford (1886) during which the large-scale rainfall over the monsoon zone is interrupted for several days in the peak monsoon months of July-August have been called 'breaks' in the monsoon in meteorological literature for over a hundred years (e.g., IMD 1888; Malurkar 1950; Ramamurthy 1969; Raghavan 1973; Krishnamurti and Bhalme 1976; Alexander et al 1978; Sikka 1980 etc.). Active spells of the monsoon are the spells characterized by 'height of rains' over the monsoon zone.

The phenomenon of breaks has been of great interest because of the relationship of the interannual variation of the monsoon rainfall over the Indian region with the occurrence of breaks. Ramdas's comparison of the variation of weekly rainfall over the so-called central provinces and central India during the excess monsoon year of 1917 and the deficit year of 1918 in figure 3(a) (after Normand 1953) clearly showed the impact of the long dry spell on the monsoon rainfall during 1918.
Krishnamurti and Bhalme (1976) showed that the major difference between the rainfall variation in good and some poor monsoon seasons is the occurrence of a long dry spell (break) in the latter. This is clearly seen in the variation of the daily rainfall over central India $\left(75^{\circ}-85^{\circ} \mathrm{E}, 15^{\circ}-25^{\circ} \mathrm{N}\right)$ for the poor monsoon season of 1972 with a long break and the good monsoon season of 1975 depicted in figure 3(b). Sikka (1980) also showed that the average number of break days in poor monsoon years is much larger than that in good monsoon years. Hence, understanding the break monsoon is not only important for prediction of this important event on the intraseasonal scale, but may also pave the way for understanding the poor monsoon seasons or droughts.

Although interruption of monsoon rainfall is recognized as the most important feature of the 'break', the criterion used by Indian meteorologists for identifying a 'break' is the synoptic situation associated with such a rainfall anomaly, rather than the rainfall distribution itself. The definition of breaks used by the India Meteorological Department (IMD) over the past several decades is given by Rao (1976) as follows - "There are periods when the monsoon trough is located close to the 


\section{CENTRAL PROVINCES \\ \& CENTRAL INDIA}
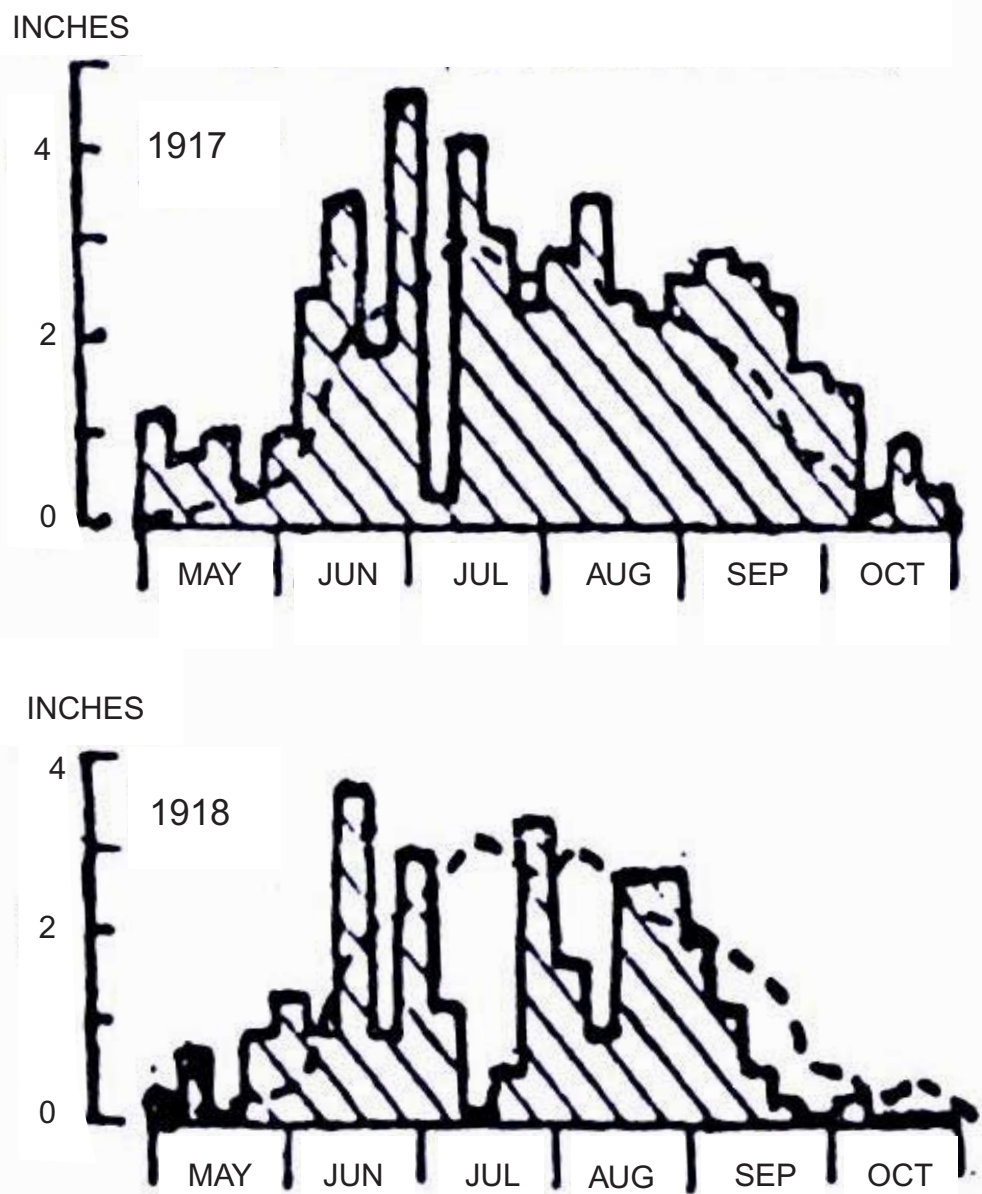

Figure 3(a). Rainfall over Central India Province during 1917, 18 (after Ramdas).

foothills of the Himalayas, which leads to a striking decrease of rainfall over most of the country, but increase along the Himalayas, parts of northeast India and southern peninsula". In Ramamurthy's (1969) comprehensive study of breaks during 18881967, a break situation was defined as one in which the trough of low pressure was not seen on the surface chart and easterlies were practically absent. Thus the break was defined in terms of surface pressure distribution and circulation rather than of rainfall. The average (or composite) anomalies of rainfall associated with breaks over meteorological subdivisions of India derived by Ramamurthy (1969) are depicted in figure 4. It should be noted that the maximum departure of rainfall occurs over the monsoon zone during the break. Subsequent to Ramamurthy's (1969) classic work, De et al (1998) have identified the breaks (according to the IMD definition) during 1968-1996.

A large number of studies have elucidated the morphology of breaks (e.g., Ramamurthy 1969; Raghavan 1973). De and Mukhopadhyay (2002) have also studied the characteristics of the transition to a break and revival from a break. The break phase is characterized by a marked change in the lower tropospheric circulation over the monsoon zone, with the vorticity above the boundary layer becoming anticyclonic (Ramamurthy 1969; Sikka and Gadgil 1978). On the other hand, active spells are characterized by a sequence of time-clustering, partly overlapping development of monsoon disturbances (T Murakami 1976) and cyclonic vorticity above the boundary layer (Sikka and Gadgil 1978). During weak spells, the strength of the cyclonic vorticity and the rainfall over the monsoon zone is much less than during active spells. Fluctuations between active spells and weak spells of rainfall occur every year. For example such fluctuations are seen in both the years shown in figure 3 . The break is a special case of a weak spell with well defined circulation characteristics which does not occur in every monsoon season (Ramamurthy 1969). During long intense breaks, the surface temperature increases rapidly and a heat-low type circulation 

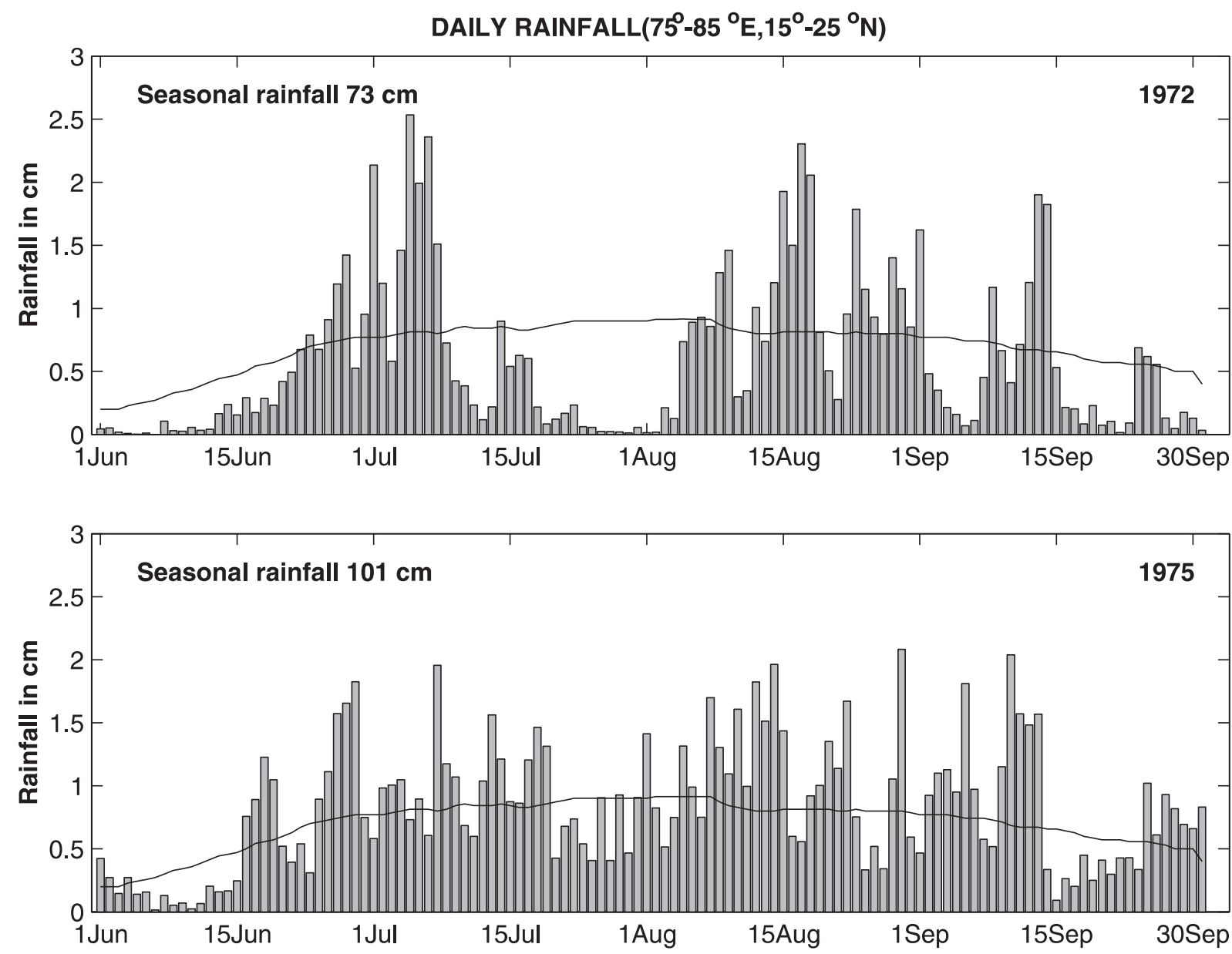

Figure 3(b). Daily rainfall over central India $\left(75^{\circ}-85^{\circ} \mathrm{E}, 15^{\circ}-25^{\circ} \mathrm{N}\right)$ during the summer monsoon of 1972 (above) and 1975 (below).

gets established over the monsoon zone with subsidence over most of the troposphere, no disturbances are generated and the prominent trough at $700 \mathrm{hpa}$ (associated with large-scale monsoon rainfall) disappears (Raghavan 1973). The occurrence of a heat low type circulation in the peak monsoon months of July and August over the monsoon zone in place of a TCZ, implies a major transition. Revival of the monsoon occurs with a TCZ again being established over the region (Sikka and Gadgil 1980). Such a transition from a heat low characterizing the premonsoon phase, also occurs during the onset phase of the monsoon. Unravelling the factors/mechanisms which lead to these transitions between heat low and TCZ and hence prediction of these transitions is one of the most challenging problems in monsoon meteorology today.

As noted, the break monsoon is operationally defined in terms of a criterion involving the surface pressure/circulation distribution and it is implicitly assumed that a rainfall anomaly pattern of the type figure 4 will always be associated with such a distribution of pressure. We believe that it would be useful to define the break monsoon (and active monsoon as well) on the basis of rainfall and its distribution rather than in terms of the circulation or the pressure distribution. Rainfall is considered to be the most important facet of the monsoon and predictions on different timescales are required in terms of rainfall. Rainfall distribution has been the basis for studies of interannual variation of the monsoon for a long time (e.g., Parthasarathy et al 1994). Given the links between intraseasonal variation and interannual variation, it would be appropriate to identify this major event in intraseasonal variation also on the basis of rainfall distribution. In several recent studies the active and weak spells or breaks have been defined on the basis of rainfall or OLR which is a proxy for rainfall (e.g., Rodwell 1997; Krishnan et al 2000; and Annamalai and Slingo 2001). A definition of break/active monsoon in terms of rainfall distribution (and hence convection) can also facilitate analyses of the teleconnection with convection over other parts of the tropics, since global data on satellite derived convection from 1974 are readily available.

Here, we define breaks (and active spells) of the Indian monsoon in terms of the rainfall over the 


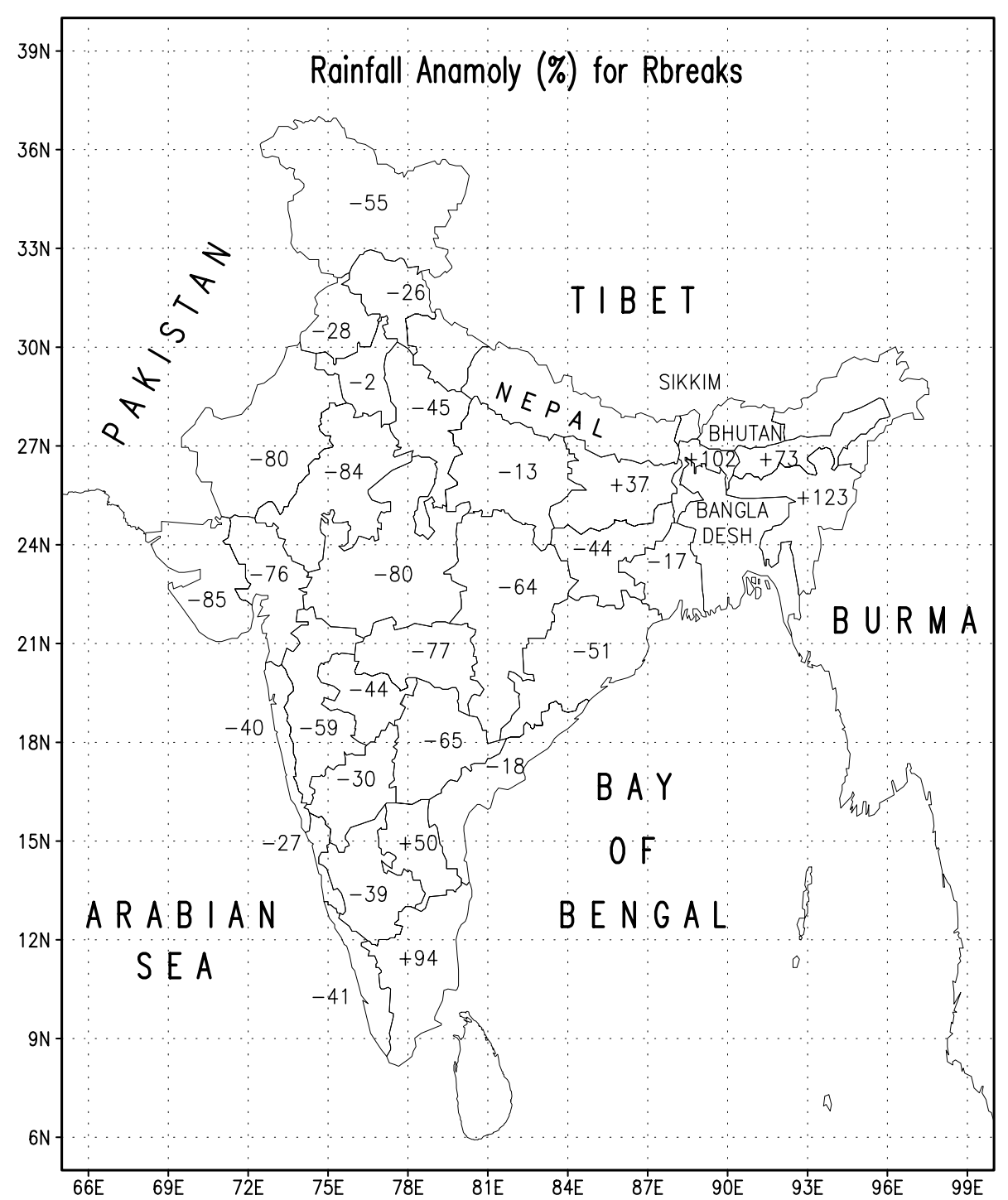

Figure 4. Rainfall anomaly (\%departure) on subdivisional scale for Ramamurthy breaks (R-breaks).

monsoon zone, during the peak monsoon months of July and August. The region over which the rainfall anomalies are considered and the part of the season (July-August) focused on, are consistent with the traditional definition used in IMD and the large body of work existing on the breaks and their impact on interannual variation of the monsoon (Koteswaram 1950; Malurkar 1950; Pisharoty and Desai 1956; Ramaswamy 1962; Mukherjee and Natarajan 1968; Ramamurthy 1969; Raghavan 1973). This has led to criteria in terms of rainfall over the monsoon zone for defining breaks. Using these criteria, we have identified the breaks (henceforth rainbreaks) for the period 1901-89. Naturally, there is a large overlap between the rainbreaks and breaks based on the traditional definition for 190167 from Ramamurthy (1969) and beyond 1967 from De et al (1998). We, therefore, suggest that this objective method based only on the rainfall distribution be used to identify breaks. Ramamurthy's
(1969) classic study also elucidated the morphology of the opposite state viz., the active spell. We have also identified active and intense spells of the monsoon using thresholds for rainfall over the monsoon zone. We have derived the circulation and OLR patterns associated with the rainbreaks and active spells.

Identification of these breaks and the associated circulation and convection patterns is only the first step which is a prerequisite to understanding the factors that lead to breaks and the revival of the monsoon at the end of the breaks. These factors/mechanisms have to be unraveled using models that can simulate them realistically. However, simulation of even the mean seasonal rainfall pattern over the Indian region has proved to be a challenge for atmospheric general circulation models (Sperber and Palmer 1996; Gadgil and Sajani 1998). A realistic simulation of the intraseasonal variation has proved to be even more difficult 
(Slingo et al 1996; Sperber et al 2000). We expect the results presented here to be useful at least for the assessment of the skill of simulation of these major events in the intraseasonal variation of the monsoon.

Although, traditionally the term 'break' refers to very weak spells of rainfall over the Indian monsoon zone, different scientists have used the same term, to denote different features of convection and/or circulation over different regions. Thus Webster et al (1998) use the term 'break' as defined by Magana and Webster (1996) to denote weak spells of convection and $850 \mathrm{hpa}$ zonal winds over a larger scale region $\left(65^{\circ}-95^{\circ} \mathrm{E}, 10^{\circ}-20^{\circ} \mathrm{N}\right)$, because it is believed that breaks in the Indian monsoon are on a scale which is much larger than India or even south Asia. On the other hand, Goswami and Mohan (2000) define 'breaks' on the basis of the strength of the $850 \mathrm{hpa}$ wind at the single gridpoint $15^{\circ} \mathrm{N}, 90^{\circ} \mathrm{E}$. Even when the so-called breaks are identified in terms of rainfall or convection over the Indian region, a variety of definitions are used. Rodwell (1997) and Annamalai and Slingo (2001) use the term 'break' to denote weak spells of the daily all-India average rainfall (calculated operationally by IMD), whereas Cadet and Daniel (1988) denote the weak spells of the average rainfall at fifteen stations distributed throughout India as breaks in the monsoon. Krishnan et al (2000) define break days as days with positive outgoing long wave radiation (OLR) anomalies over northwest and central India (i.e., mainly over the western part of the monsoon zone), provided the average OLR anomaly over $73^{\circ}-82^{\circ} \mathrm{E}, 18^{\circ}-28^{\circ} \mathrm{N}$ exceeds $10 \mathrm{wm}^{-2}$.

There is another difference in the approach to the definition of breaks in these studies vis-a-vis the traditional approach. In the traditional approach, "break" is defined as an event with specified characteristics e.g., the surface pressure pattern. However, in several studies such as Annamalai and Slingo 2001 (henceforth AS) and Goswami and Mohan 2000 (henceforth GM), the active spells and breaks are identified as crests/troughs of a specific mode (e.g., 30-50 day) of an appropriate field (e.g., 850 hpa zonal wind in GM). Thus the composite or anomaly pattern in such cases is associated with active spells or 'breaks' corresponding to only one specific mode.

There are differences in the duration of breaks identified in different studies, their frequency of occurrence as well as the associated circulation and convection patterns because the definition of "breaks" is based on different criteria. Use of the term 'break' for weak spells of convection/circulation over regions of varying spatial scale has led to considerable confusion. We believe that it is important to avoid using the same term to denote events/phenomena with different circulation and convection patterns. It is necessary to assess the extent to which the 'breaks' identified on the basis of specific criteria overlap with the traditional breaks before the results presented in these studies (such as the elucidation of the nature of transition to a break by westward propagation of suppressed convection over the Bay of Bengal suggested by Krishnan et al 2000) and the underlying mechanisms can be considered to be relevant to the break monsoon studied extensively by monsoon meteorologists for over five decades. We have compared the rainbreaks identified here, the breaks of Webster et al (1998) and Krishnan et al (2000) and the breaks identified by Ramamurthy (1969) and De et al (1998).

The data analyzed are described in the next section. In section 3, we discuss the identification of breaks on the basis of the rainfall over the monsoon zone and compare these breaks with breaks defined using different criteria. Active and intense spells of the monsoon are considered and the relationship of interannual variation of the Indian summer monsoon rainfall to breaks and active spells is discussed in section 4 . The patterns of rainfall, convection (OLR) and circulation associated with these breaks and active spells are presented in section 5 .

\section{Data}

The basic rainfall data we analyzed comprise (i) daily rainfall during June to September at 273 welldistributed stations over the Indian region for the period 1901-1989 obtained from the India Meteorological Department and (ii) all-India average summer monsoon rainfall derived by Parthasarthy et al (1994). Satellite derived OLR (Gruber and Krueger 1984) has been extensively used as a proxy for rainfall in the tropics. Weak spells of convection/precipitation over different regions have been identified on the basis of OLR anomalies (e.g., Webster et al 1998; Krishnan et al 2000). It is important to note that in the OLR derived from the NOAA series of satellites, there is a systematic bias (Gadgil and Asha 1992). Waliser and Zhou (1997) have suggested a novel method for removing the bias due to variation in satellite equatorial crossing time from monthly OLR data sets. Lucas et al (2000) have estimated the bias in the daily OLR data sets and removed them to produce an unbiased OLR series. We have analysed these unbiased OLR data to determine the patterns associated with breaks and active spells of the monsoon. Circulation patterns are obtained by analysis of the daily average data of NCEP-NCAR project (Kalnay et al 1996). 


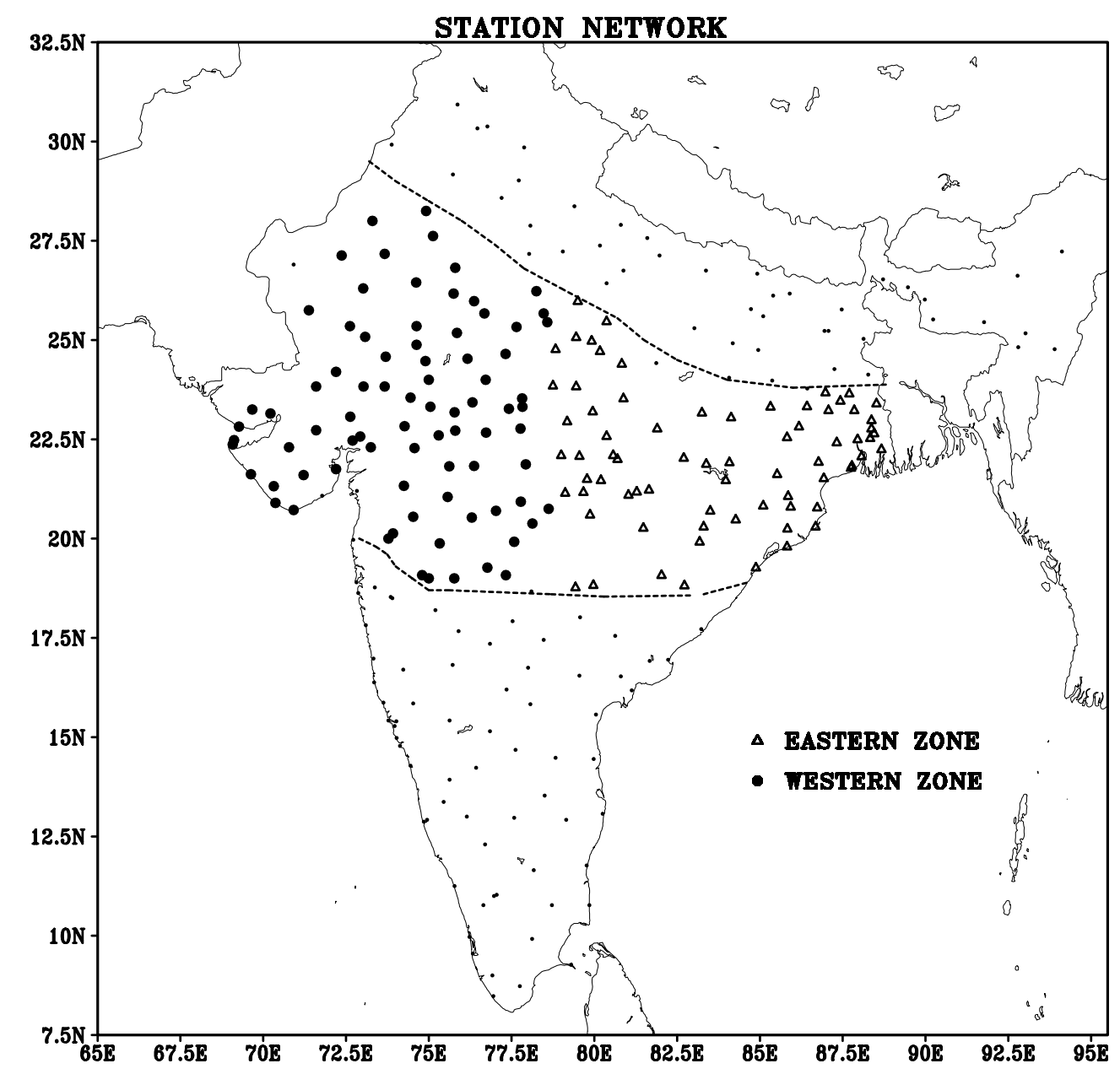

Figure 5(a). Rainfall station network and the monsoon zone; stations in the eastern and western subzones of the monsoon zone are represented by triangles and circles respectively.

\section{Identification of breaks}

\subsection{Rainfall over the monsoon zone}

The network of stations and the monsoon zone within which the large-scale monsoon rainfall occurs is depicted in figure 5(a). The variation of the all-India summer monsoon rainfall is highly correlated with the variation of the summer monsoon rainfall over the monsoon zone (figure $5 \mathrm{~b}$ ). We note that the breaks identified by Ramamurthy (1969) are associated with large negative anomalies of rainfall over the monsoon zone (figure 4) and use a criterion based on the rainfall over the monsoon zone to define a break. It is seen from figure 2 that the mean July-August rainfall varies considerably across the monsoon zone with that over the eastern part being much larger than that of the western part. Furthermore, the normalized anomaly (percentage departure) of the rainfall during breaks is much larger over the western part than the eastern part (figure 4). This suggests that the threshold for rainfall used for identifying the break has to be lower over the western part. We, therefore, divide the monsoon zone into two subzones: the eastern and the western zones, which are delineated so as to maximize the cross correlation between the time series (of daily and five day running mean rainfall) at different stations within each zone. These zones are indicated in figure 5(a) with distinct symbols for stations assigned to the two zones.

The temporal variation of the average rainfall of any region/zone can be considered to be a meaningful representation of the temporal variation at the stations within the region/zone, only if the variations at the different stations are coherent i.e., tend to occur in phase so that the zonal average rainfall is well correlated with that at the different stations. The correlations of the zonal average rainfall of the eastern and western zones with the rainfall at different stations within each zone are found to be significant at $1 \%$ level. We find that most of the stations in these zones are well correlated with the zonal average. The correlation coefficient of over $80 \%(75 \%)$ of the stations in eastern (western) zone with the zonal average is above $0.4(0.3)$. 


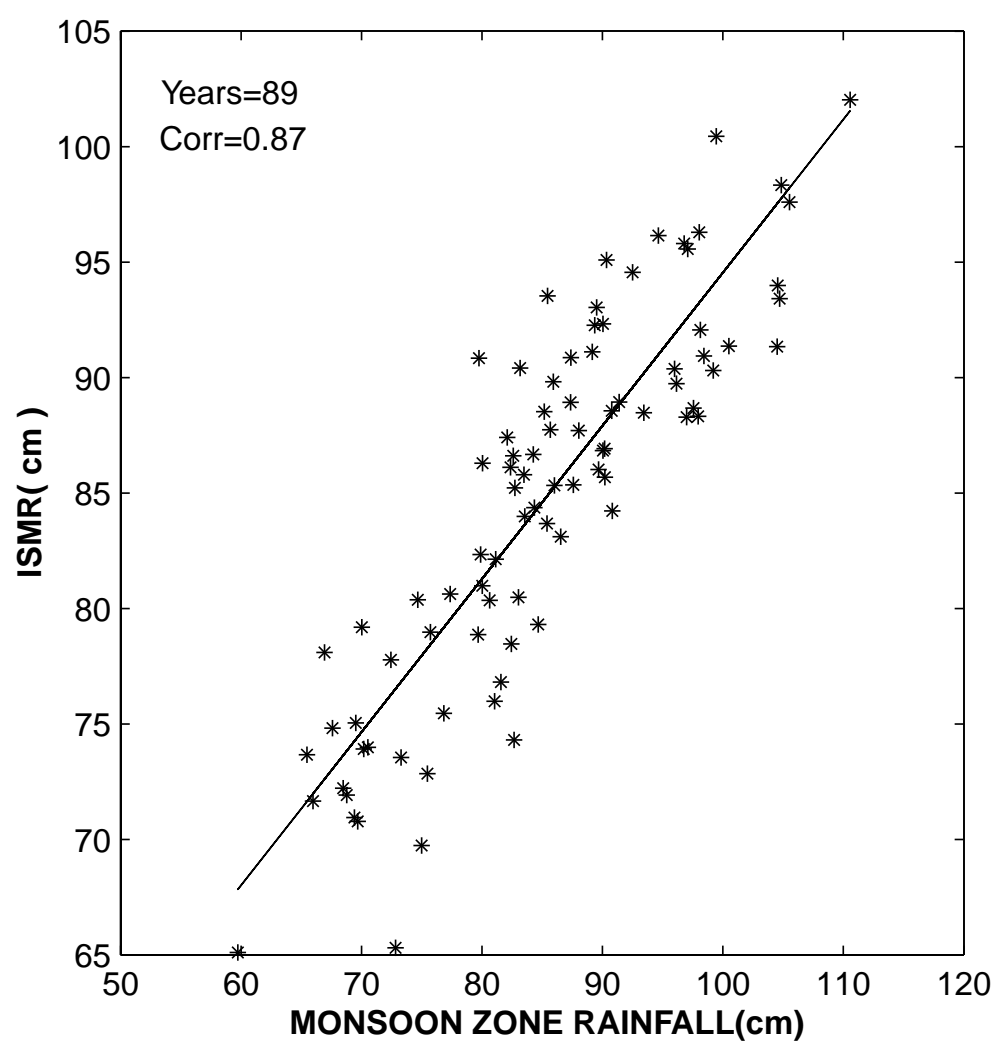

Figure 5(b). Variation of the all-India rainfall with the rainfall of the monsoon zone for the summer monsoon season.

Thus the zonal average rainfall can be considered to be a meaningful representation of the rainfall at the stations within each of the zones.

The major characteristic of the rainfall pattern during a break (active spell) is a substantial decrease (increase) over the monsoon zone. Breaks are also characterized by well-defined anomalies in the pressure distribution and circulation of the lower troposphere. For such an association of the anomaly patterns of rainfall and pressure/circulation, the duration of the break has to be sufficiently long relative to the time taken for transition to the break phase. There is no consensus on what is a sufficiently long duration for the equilibrium between circulation/pressure and rainfall anomalies to be attained, but it is believed that it is more than one or two days. In his classic study of breaks, Ramamurthy (1969) considered the minimum life-span of a break to be three days. Intense breaks that are associated with major changes in circulation (such as the heat-low developing over the region characterized by moist convection in the mean pattern), are generally breaks of duration more than five days. Such prolonged breaks also have a major impact on the seasonal rainfall.

\subsection{Rainfall thresholds}

We identify breaks on the basis of the values of the average daily rainfall of the eastern and western zones. We define a break day as one in which the average rainfall over each of these zones is below the specified thresholds. The mean and standard deviation for the daily average rainfall over the western zone are found to be $6.62 \mathrm{~mm} /$ day and $6.27 \mathrm{~mm} /$ day and for the eastern zone $11.17 \mathrm{~mm} /$ day and $7.55 \mathrm{~mm} /$ day respectively. While the mean rainfall over the eastern zone is higher, the percentage departure during breaks is smaller relative to that over the western zone (figure 4). Hence the threshold over the eastern zone has to be higher than that over the western zone.

The percentage of days during July-August for different rainfall ranges for western and eastern zone is given in table 1 . It is seen that in the peak monsoon in months of July-August the zonal average rainfall is zero only on $1.6 \%$ of days for the western and $0.07 \%$ days for the eastern zone. About $33 \%$ of the days have rainfall less than $2.5 \mathrm{~mm}$ /day over the western zone and about $38 \%$ have rainfall less than $7.5 \mathrm{~mm} /$ day over the eastern zone. We find that when these are chosen as the threshold values for the western zone and the eastern zone respectively, the breaks identified are by and large consistent with the breaks from the large body of literature on the subject (e.g., Ramamurthy 1969; Raghavan 1973; Sikka 1980; etc). During 1901-89, rainfall was below the thresholds in the western and eastern zones simultaneously on $16 \%$ of the days. 
Table 1. Percentage of days in July-August with rainfall $(\mathrm{mm} /$ day $)$ in different ranges.

\begin{tabular}{ccc}
\hline & Western zone & Eastern zone \\
\hline 0 & 1.58 & 0.07 \\
\hline $0-2.5$ & 31.39 & 7.54 \\
\hline $2.5-5.0$ & 17.18 & 13.92 \\
\hline $5.0-7.5$ & 14.04 & 16.33 \\
\hline $7.5-10.0$ & 11.27 & 14.15 \\
\hline $10-12.5$ & 8.66 & 12.81 \\
\hline $12.5-15.0$ & 5.55 & 9.82 \\
\hline $15.0-17.5$ & 3.66 & 7.43 \\
\hline $17.5-20.0$ & 2.48 & 4.98 \\
\hline $20.0-22.5$ & 1.61 & 4.19 \\
\hline $22.5-25.0$ & 0.94 & 2.77 \\
\hline $25.0-27.5$ & 0.58 & 1.94 \\
\hline $27.5-30.0$ & 0.49 & 1.54 \\
\hline $30.0-40.0$ & 0.54 & 2.25 \\
\hline $40.0-50.0$ & 0.02 & 0.25 \\
\hline $50.0-60.0$ & 0.00 & 0.00 \\
\hline
\end{tabular}

The time-series of the rainfall for the eastern and western zones during July-August summer monsoon of 1972 are shown in figure 6. For this season, De et al (1998) identified the break period as 17th July - 3rd August. With the assumed thresholds, the long break is split into two parts 19th22nd July and 24th July-3rd August, because the rainfall on 23rd July over the eastern zone is slightly higher than the threshold. For supersynoptic scale breaks such as this one, such a gap of one day can be ignored provided that the rainfall on such a day between two break spells is not high. When two break spells are separated by one day, we check whether the three day running mean for that day is below slightly more stringent thresholds $(2 \mathrm{~mm} /$ day for western and $7 \mathrm{~mm} /$ day for eastern zone respectively) and, if so, include the day in the break. It is seen that the specified thresholds for the western and eastern macro-zones yield a break period that has a very large overlap with the break identified by De et al (1998).

We, therefore, choose the thresholds of 2.5 and $7.5 \mathrm{~mm}$ /day for the western and eastern zone respectively for identification of breaks, adopting slightly less stringent thresholds for removing one day gaps between breaks. The results are not very sensitive to the variation of the thresholds for rainfall of the western and eastern zones within a reasonable range.

\subsection{Comparison of rainbreaks and breaks based on other criteria}

For 1901-67 the breaks identified on the basis of the specific thresholds for the rainfall of the western and eastern zones (which we henceforth refer to as rainbreaks), and the breaks identified in the classic study by Ramamurthy (1969) (which we henceforth refer to as R-breaks) are given in table 2 . The rainbreaks identified here for July-August during 1968-89 are given along with those identified by De et al (1998) (henceforth D-breaks), by Webster et al 1998 (henceforth W-breaks) and by Krishnan et al 2000 (henceforth K-breaks) in table 3 for July-August in the overlapping years. In tables 2 and 3 we have included rainbreaks of duration two days and longer to ascertain the overlap with breaks identified in other studies. However, when investigating other aspects such as the frequency of occurrence of breaks of different duration, or relationship with seasonal rainfall, we have considered only breaks of duration of three days or longer.

It is seen from table 2, that on the whole, there is good agreement between R-breaks and rainbreaks. The results are rather similar particularly for long breaks e.g., July 1966. During 1901-67, there were 89 R-breaks. In 65 of these breaks, rainbreaks also occurred with varying degree of overlap. In the remaining 24 R-breaks, the rainfall was above the threshold values specified, and no rainbreak occurred. A majority of these 24 cases (i.e., 22 cases) were of relatively short duration (3 to 5 days). However, there was one case each of seven and twelve days. While we expect some discrepancies between the breaks determined on the basis of rainfall and those identified from pressure/wind distribution for relatively short period breaks, which could be dominated by transients, the results for the two long breaks were surprising. The rainfall variation in the monsoon zone for one such season viz., 1954 is shown in figure 7. It is seen that within the R-break of 18th-29th July, the rainfall over the eastern zone was below our threshold of $7.5 \mathrm{~mm}$ on almost all the days except for a short spell during 22nd, 23rd July and over the western zone low but slightly above the threshold on several days. In this case, a slightly less stringent threshold for the western zone would have implied rainbreaks overlapping with some parts of the R-break. However 22nd, 23rd July would not have been considered as rainbreak days. It is possible that the surface trough did not shift from its northern location in this short rainfall spell and hence R-break extended for a few days beyond this. During the seven day rainbreak of 1967 also, the rainfall over the eastern zone exceeded the threshold on one day. We may, therefore, conclude that 

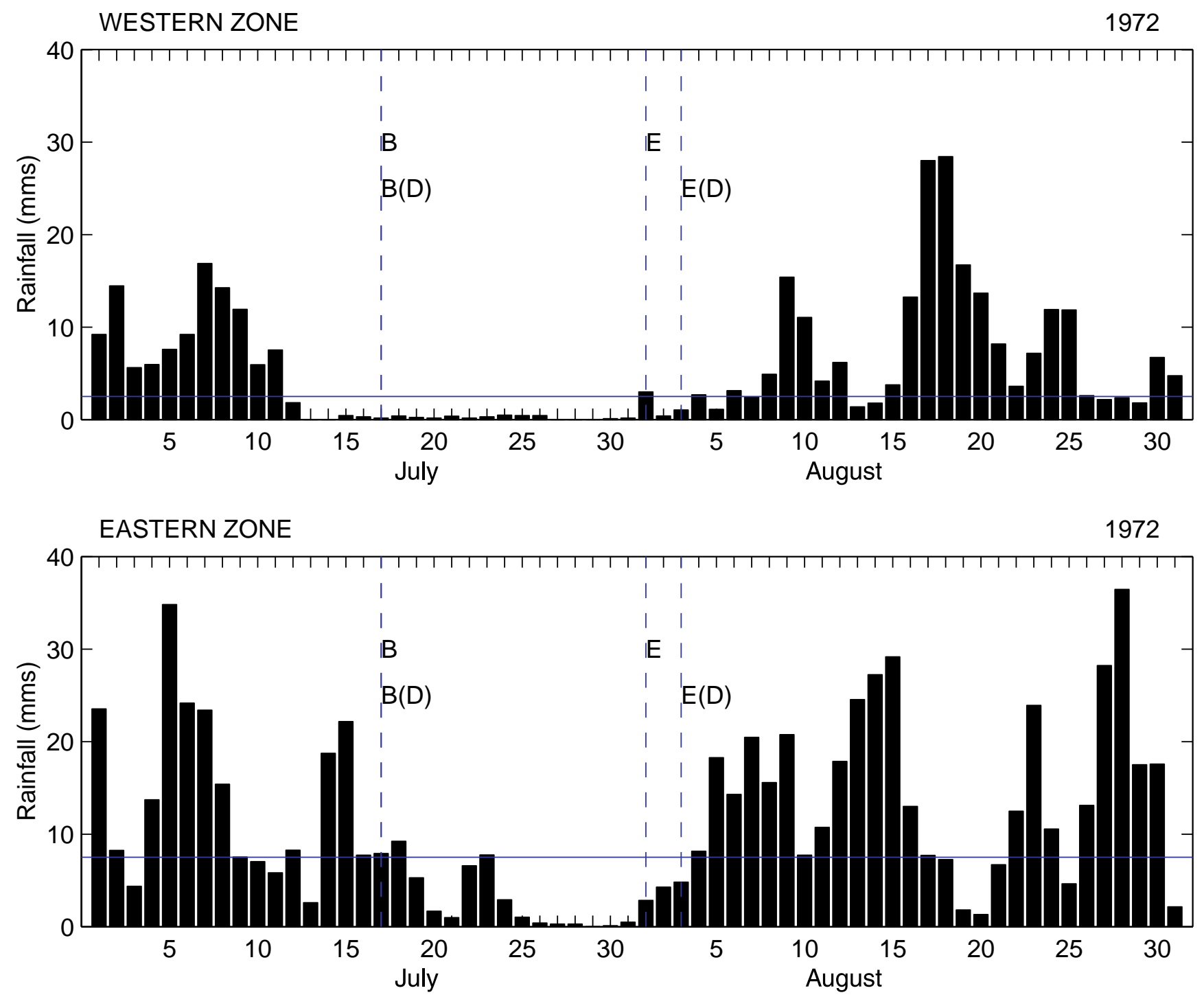

Figure 6. Time-series of the daily rainfall over the western, eastern zones and the all-India average rainfall during July-August 1972. The five day running mean is also shown.

our definition of breaks as interruption of the rainfall in the monsoon zone, which is by and large consistent with that of Ramamurthy (1969) and IMD definition, is a reasonable one.

The composite patterns of rainfall and anomaly for the rainbreaks during 1901-89 are shown in figure $8(a, b)$. It is seen that the anomaly pattern of figure $8(\mathrm{~b})$, which is derived from the percentage departure of rainfall at each of the 273 stations during breaks over the Indian region, is very similar to the anomaly pattern for R-breaks on the subdivisional scale (figure 4) with large negative anomalies over the monsoon zone with highest anomalies over the western part. The rainfall anomalies over the west coast are also negative. The amplitudes of the anomalies at the station scale are larger than those of the subdivisions. Note that the average rainfall at stations during breaks within the western and eastern zones (figure 8a) is much lower than the assumed thresholds of $2.5 \mathrm{~mm}$ and $7.5 \mathrm{~mm}$ per day. The frequency distribution of duration of rainbreaks for the period 1901-89 is found to be similar to that of R-breaks during 1901-67 (table 4).

As expected, there is considerable overlap of the rainbreaks with D-breaks which are based on the IMD definition (table 3). K-breaks are associated with weak spells primarily over the western zone. This is clear from the definition and also the OLR anomaly pattern of the breaks, which has a large negative anomaly over the eastern zone (their figure 4e). However, conventional breaks are associated with negative rainfall anomalies over the eastern zone as well (see figure 4, for Ramamurthy break). Due to this difference between their definition and the traditional one, while some of the breaks identified by Krishnan et al (2000) coincide with rainbreaks (e.g., 1982), others do not. For example in 1987, the rainfall over the eastern 
Table 2. Breaks during July-August 1901-67.

\begin{tabular}{|c|c|c|}
\hline Year & Rainbreak days & R-break days ${ }^{\dagger}$ \\
\hline 1901 & 1-4J, 13-15J & $12-15 \mathrm{~J}$ \\
\hline 1902 & $1-3 \mathrm{~A}, 5-10 \mathrm{~A}, 12-16 \mathrm{~A}$ & $9-15 \mathrm{~A}$ \\
\hline 1903 & $11-15 \mathrm{~A}, 27-30 \mathrm{~A}$ & $12-15 \mathrm{~A}$ \\
\hline 1904 & $12-14 \mathrm{~J}, 26-27 \mathrm{~J}, 17-19 \mathrm{~A}, 25-28 \mathrm{~A}$ & $12-14 \mathrm{~J}, 25-29 \mathrm{~J}$ \\
\hline 1905 & $15-17 \mathrm{~J}, 30 \mathrm{~J}-2 \mathrm{~A}, 4-16 \mathrm{~A}, 24-25 \mathrm{~A}$ & $15-18 \mathrm{~J}, 6-14 \mathrm{~A}$ \\
\hline 1906 & $15-17 \mathrm{~J}, 29 \mathrm{~J}-6 \mathrm{~A}, 12-16 \mathrm{~A}$ & 9-15J, 29J-18A \\
\hline 1907 & $6-10 \mathrm{~J}, 30-31 \mathrm{~A}$ & -- \\
\hline 1908 & - & $14-18 \mathrm{~J}$ \\
\hline 1909 & 21-23J, 7-8A, 11-17A & 19-22J, 4-19A \\
\hline 1910 & $11-21 \mathrm{~J}, 14-20 \mathrm{~A}$ & 8-20J, 24-27J, 15-17A \\
\hline 1911 & 1-5J, 15-27J, 30-31J, 11-13A, 26-28A & $15-25 \mathrm{~J}$ \\
\hline 1912 & $1-3 \mathrm{~J}, 18-25 \mathrm{~A}$ & $13-23 \mathrm{~A}$ \\
\hline 1913 & $1-5 \mathrm{~J}, 9-21 \mathrm{~A}$ & 1-4J, 10-12J, 12-20A \\
\hline 1914 & $26-31 \mathrm{~A}$ & $1-4 \mathrm{~A}, 10-13 \mathrm{~A}, 26-31 \mathrm{~A}$ \\
\hline 1915 & 7-13J, 10-18A, 26-27A & $6-12 \mathrm{~J}, 9-17 \mathrm{~A}$ \\
\hline 1916 & 1-3J, 18-19J & $9-11 \mathrm{~A}$ \\
\hline 1917 & $7-12 \mathrm{~J}$ & $5-11 \mathrm{~J}, 25-27 \mathrm{~J}$ \\
\hline 1918 & 10-26J, 7-8A, 11-13A & $7-23 \mathrm{~J}, 7-12 \mathrm{~A}$ \\
\hline 1919 & - & $15-18 \mathrm{~J}$ \\
\hline 1920 & 1-2J, 10-11A, 13-18A, 20-22A, 30-31A & 18-20J, 9-14A, 18-20A \\
\hline 1921 & 1-5J, 4-5A, 19-22A & 1-4J, 15-17A, 27-30A \\
\hline 1922 & $7-12 \mathrm{~A}, 24-25 \mathrm{~A}$ & $7-13 \mathrm{~A}$ \\
\hline 1923 & $9-10 \mathrm{~A}$ & - \\
\hline 1924 & 20-21J, 14-20A & $12-19 \mathrm{~A}$ \\
\hline 1925 & $1-2 \mathrm{~J}, 26-27 \mathrm{~A}$ & $22-24 \mathrm{~J}, 9-12 \mathrm{~A}$ \\
\hline 1926 & - & 16-21J, 29-31A \\
\hline 1927 & $1-6 \mathrm{~A}$ & $1-5 \mathrm{~A}$ \\
\hline 1928 & 30J-1A, 3-10A, 13-16A & $3-14 \mathrm{~A}$ \\
\hline 1929 & $2-3 \mathrm{~J}, 6-7 \mathrm{~A}, 10-12 \mathrm{~A}$ & - \\
\hline 1930 & $13-14 \mathrm{~A}, 16-25 \mathrm{~A}, 30-31 \mathrm{~A}$ & $22-28 \mathrm{~A}$ \\
\hline 1931 & $10-11 \mathrm{~J}, 24-25 \mathrm{~J}$ & - \\
\hline 1932 & $20-31 \mathrm{~A}$ & $9-28 \mathrm{~A}$ \\
\hline 1933 & 3-11J, 14-18A & $13-20 \mathrm{~A}$ \\
\hline 1934 & $13-18 \mathrm{~J}, 24-26 \mathrm{~J}$ & 11-18J \\
\hline 1935 & $8-11 \mathrm{~A}, 20-21 \mathrm{~A}, 24-26 \mathrm{~A}$ & 8-10A, 19-23A \\
\hline 1936 & 9-11J, 14-15J, 30-31J, 14-15A, 24-25A, 27-28A & - \\
\hline 1937 & 31J-1A, 10-13A, 16-19A, 29-31A & $8-15 \mathrm{~A}$ \\
\hline 1938 & $1-2 \mathrm{~J}, 17-18 \mathrm{~A}$ & - \\
\hline 1939 & $1-2 \mathrm{~J}, 10-14 \mathrm{~A}$ & $25-28 \mathrm{~J}$ \\
\hline 1940 & $29-31 \mathrm{~A}$ & - \\
\hline
\end{tabular}


Table 2. (Continued).

\begin{tabular}{|c|c|c|}
\hline 1941 & 16-26J, 5-6A, 22-29A & $16-24 \mathrm{~J}$ \\
\hline 1942 & $14-15 \mathrm{~A}$ & $7-10 \mathrm{~A}$ \\
\hline 1943 & 11-16A, 29-30A & - \\
\hline 1944 & - & - \\
\hline 1945 & $1-7 \mathrm{~A}$ & $29 \mathrm{~J}-9 \mathrm{~A}$ \\
\hline 1946 & 9-11J, 29-30A & 9-11J, 29-31A \\
\hline 1947 & 9-10J, 2-3A, 7-8A & $6-9 \mathrm{~J}, 3-10 \mathrm{~A}$ \\
\hline 1948 & $3-5 \mathrm{~J}, 31 \mathrm{~J}-1 \mathrm{~A}$ & $1-3 \mathrm{~A}$ \\
\hline 1949 & $11-12 \mathrm{~A}, 20-26 \mathrm{~A}$ & 19-23J, 21-25A \\
\hline 1950 & $2-3 \mathrm{~J}, 15-27 \mathrm{~A}$ & $15-24 \mathrm{~A}$ \\
\hline 1951 & 14-15J, 24-30A & 1-3J, 11-13J, 15-17J, 24-29A \\
\hline 1952 & 1-3J, 10-13J, 27-30A & $9-12 \mathrm{~J}$ \\
\hline 1953 & - & 24-26J \\
\hline 1954 & $22-29 \mathrm{~A}$ & 18-29J, 21-25A \\
\hline 1955 & 24-25J & 22-29J \\
\hline 1956 & $23-30 \mathrm{~A}$ & $23-26 \mathrm{~A}$ \\
\hline 1957 & 28-29J & $27-31 \mathrm{~J}, 5-7 \mathrm{~A}$ \\
\hline 1958 & - & $10-14 \mathrm{~A}$ \\
\hline 1959 & - & $16-18 \mathrm{~A}$ \\
\hline 1960 & 20-24J, 30-31A & $16-21 \mathrm{~J}$ \\
\hline 1961 & - & - \\
\hline 1962 & $27-28 \mathrm{~J}, 1-2 \mathrm{~A}, 7-8 \mathrm{~A}, 25-26 \mathrm{~A}$ & $18-22 \mathrm{~A}$ \\
\hline 1963 & 18-19J, 22-23J & 10-13J, 17-21J \\
\hline 1964 & - & 14-18J, 28J-3A \\
\hline 1965 & 7-11J, 4-14A & $6-8 \mathrm{~J}, 4-15 \mathrm{~A}$ \\
\hline 1966 & $2-12 \mathrm{~J}, 22-31 \mathrm{~A}$ & 2-11J, 23-27A \\
\hline 1967 & $6-15 \mathrm{~J}$ & $7-10 \mathrm{~J}$ \\
\hline
\end{tabular}

${ }^{\dagger}$ Only breaks of duration three days or longer have been listed.

zone was rather large on some days in the long K-break of 14th July-3rd August (figure 9), and the period is not identified as a long D-break or a rainbreak. However, there is some overlap with one D-break (lasting 4 days) and three rainbreaks (two of two days each and one of four days) occurring in this long K-break. Long breaks are of particular interest because Raghavan (1973) has shown that they involve a transition of the circulation to a heat trough like circulation with descent at and above $700 \mathrm{hPa}$. Given the occurrence of rainfall on several days in the monsoon zone in this long K-break, it is clear that such a transition did not take place. Thus the criteria adopted by Krishnan et al (2000) do not always lead to the break monsoon based on the traditional definition studied, amongst several others, by Raghavan (1973).
It is also seen from figure 9 that negative anomalies of the all-India average rainfall (AIR) operationally derived by IMD and used by Rodwell (1997) and AS for defining breaks, are not necessarily associated with low rainfall over the monsoon zone characterizing the traditional break situation. For example, negative anomalies of AIR during 5 th -9 th August occur despite events of high rainfall over the western zone during 6th-8th August and the eastern zone during 5th-6th August. In fact there was a very large deficit rainfall over the west coast of the peninsula during this K-break which may have contributed to negative anomalies of AIR.

Webster et al (1998) have defined break days as days on which OLR and $850 \mathrm{mb}$ zonal wind anomalies over $65^{\circ}-95^{\circ} \mathrm{E}, 10^{\circ}-20^{\circ} \mathrm{N}$ are greater than $10 \mathrm{Wm}^{-2}$ and less than $3 \mathrm{~m} \mathrm{sec}^{-1}$ respectively. The 
Table 3. Break days during July-August 1968-89.

\begin{tabular}{|c|c|c|c|c|}
\hline Year & Rainbreak days & D-break days ${ }^{\dagger}$ & W-break days & K-break days \\
\hline 1968 & $25-31 \mathrm{~A}$ & $25-29 \mathrm{~A}$ & & \\
\hline 1969 & $27-31 \mathrm{~A}$ & $17-20 \mathrm{~A}, 25-27 \mathrm{~A}$ & & \\
\hline 1970 & 14-19J, 23-26J & $12-25 \mathrm{~J}$ & & \\
\hline 1971 & 8-10J, 5-6A, 18-19A & $17-20 \mathrm{~A}$ & & \\
\hline 1972 & 19J-3A & $17 \mathrm{~J}-3 \mathrm{~A}$ & & \\
\hline 1973 & 24-26J, 30J-1A & 23J- $1 \mathrm{~A}$ & & \\
\hline 1974 & $24-26 \mathrm{~A}, 29-31 \mathrm{~A}$ & $30-31 \mathrm{~A}^{*}$ & & \\
\hline 1975 & - & 24-28J & & \\
\hline 1976 & $3-4 \mathrm{~J}, 21-22 \mathrm{~A}$ & - & & \\
\hline 1977 & $15-19 \mathrm{~A}$ & $15-18 \mathrm{~A}$ & & \\
\hline 1978 & - & $16-21 \mathrm{~J}$ & & \\
\hline 1979 & $2-6 \mathrm{~J}, 15-31 \mathrm{~A}$ & $17-23 \mathrm{~J}, 15-31 \mathrm{~A}^{*}$ & & 1-6J, 18-22J,12-27A \\
\hline 1980 & 17-20J, 14-15A & $17-20 \mathrm{~J}$ & 4-6J, 6-10A & \\
\hline 1981 & 19-20A, 24-31A & 26-30J, 23-27A & $2-5 \mathrm{~J}, 30-31 \mathrm{~A}$ & $23-31 \mathrm{~A}$ \\
\hline 1982 & $1-8 \mathrm{~J}$ & - & $24-26 \mathrm{~J}, 30 \mathrm{~J}-1 \mathrm{~A}$ & $1-7 \mathrm{~J}^{* *}$ \\
\hline 1983 & 8-9J, 24-26A & $22-25 \mathrm{~A}$ & $2-6 \mathrm{~J}, 4-6 \mathrm{~A}$ & $4-8 \mathrm{~J}$ \\
\hline 1984 & - & $20-24 \mathrm{~J}$ & $23 \mathrm{~J}, 27 \mathrm{~J}$ & $19-22 \mathrm{~J}$ \\
\hline 1985 & $2-3 \mathrm{~J}, 23-25 \mathrm{~A}$ & $22-25 \mathrm{~A}$ & $4-8 \mathrm{~J}$ & $1-3 J^{* *}, 23-26 \mathrm{~A}$ \\
\hline 1986 & 1-4J, 31J-2A, 22-31A & $23-26 \mathrm{~A}, 29-31 \mathrm{~A}^{*}$ & 1-3J & $20-30 A^{*}$ \\
\hline 1987 & 16-17J, 23-24J, 31J-4A, 11-13A & $28 \mathrm{~J}-1 \mathrm{~A}$ & $27-31 \mathrm{~J}, 30-31 \mathrm{~A}$ & $14 \mathrm{~J}-3 \mathrm{~A}$ \\
\hline 1988 & $14-17 \mathrm{~A}$ & $5-8 \mathrm{~J}, 13-15 \mathrm{~A}$ & - & \\
\hline 1989 & $30-31 \mathrm{~J}$ & 10-12J, 29-31J & $28 \mathrm{~J}-1 \mathrm{~A}$ & \\
\hline
\end{tabular}

${ }^{\dagger}$ Only breaks of duration three days or longer have been listed.

*Extended into September.

${ }^{* *}$ Commenced in June.

breaks thus defined have been given for MaySeptember during 1980-93. In some, (but not all) of the breaks, the rainfall anomaly is negative over the monsoon zone. There is considerable rainfall over the eastern part of the monsoon zone on two of the four W-break days of 7th, 8th August 1992 and over the western part on 5th August 1992 (figure 14 of Webster et al 1998). The duration of these Wbreaks is generally short, varying from 1 to 7 days with $90 \%$ of the breaks being of $3-5$ days duration; whereas over $30 \%$ of R-breaks and rainbreaks last for 7 days or longer and there are several years in which not a single R-break occurs. There is very little overlap between $\mathrm{W}$-breaks and rainbreaks and breaks of the Indian monsoon are generally not identified as breaks by Webster et al (1998).

Further, Webster et al (1998) state that within each monsoon season there are three or four active break sequences. This suggests that W-breaks are weak spells of the intraseasonal variation of the rainfall over the Indian region, which are known to occur every year. The 'breaks' of the 40-day mode of AS or GM also occur every year and probably correspond to weak spells of rainfall, but over parts of the Indian monsoon zone for AS and the northern part of the Bay of Bengal for GM.

\section{Active and intense spells, breaks and all India monsoon rainfall}

\subsection{Active and intense spells}

Active spells are characterized by well distributed rainfall over the monsoon zone. Hence, during active spells, we expect the rainfall to be above normal over the western as well as the eastern zone. We use thresholds of $8 \mathrm{~mm} /$ day for western zone and $12.5 \mathrm{~mm} /$ day for the eastern zone for identifying days of active spells. In each zone, rainfall higher than the specific threshold, occurs on $35 \%$ of the days. Most of the active spells (about $90 \%$ ) identified by our criterion have a duration of 1 and 2 days. Of the active spells of duration 


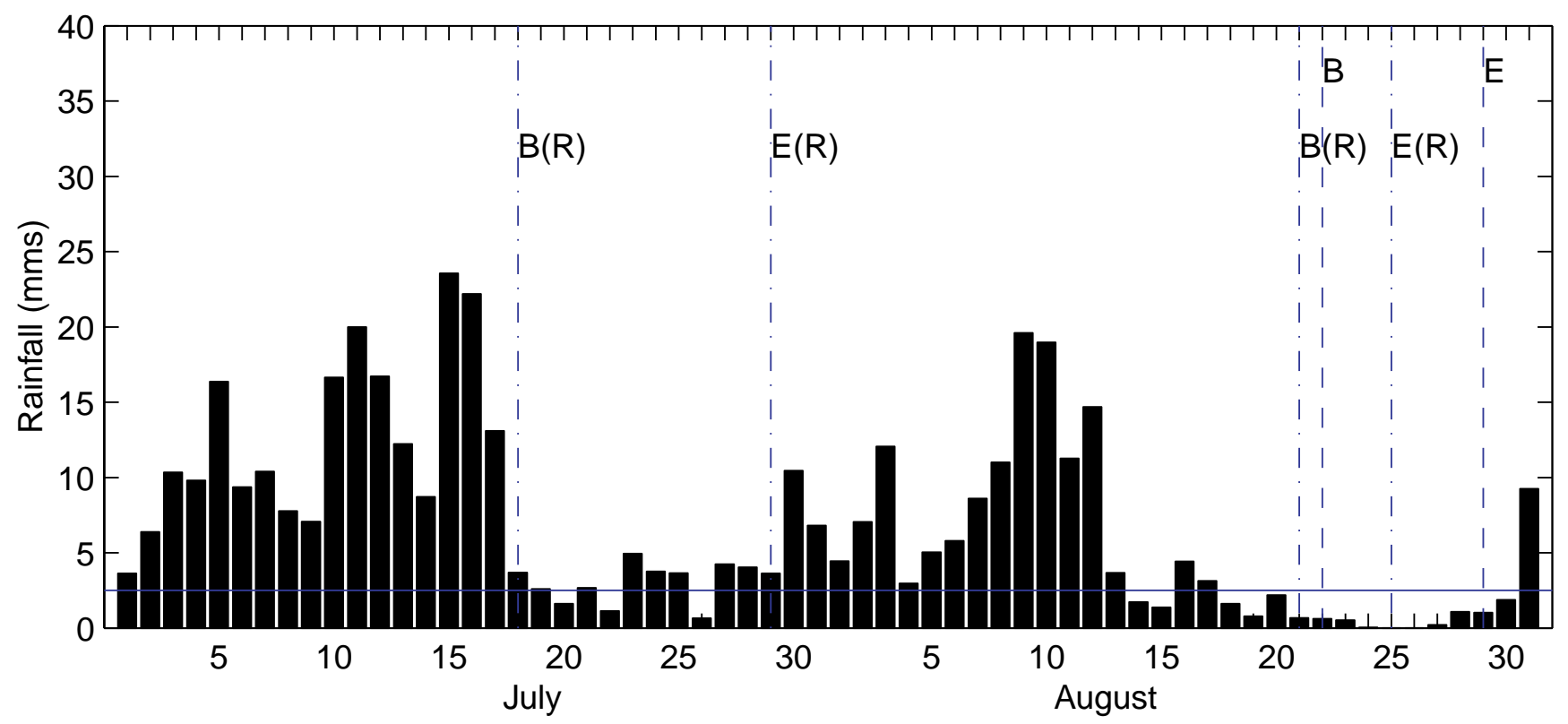

EASTERN ZONE

1954

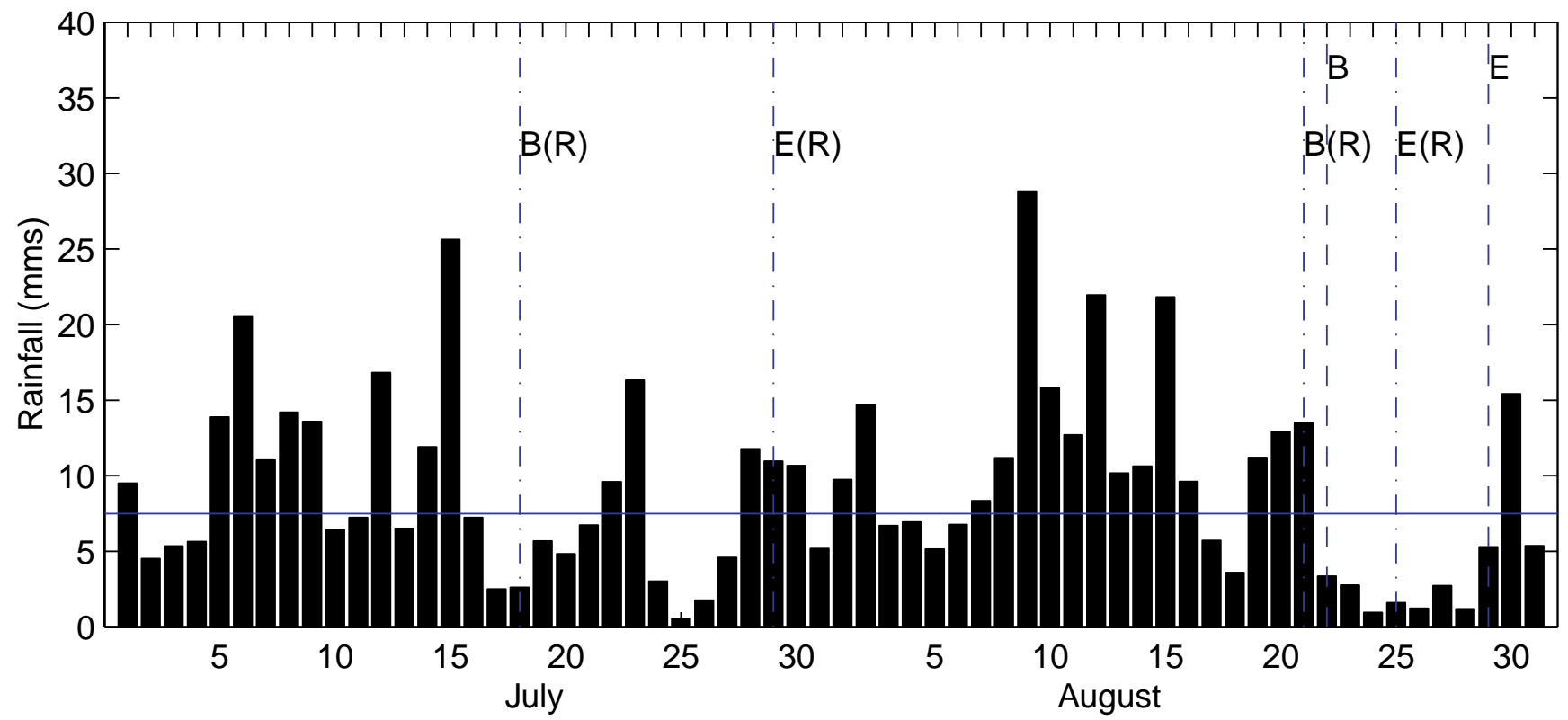

Figure 7. Daily rainfall over western and eastern zones during July-August 1954; the beginning and end of R-breaks are indicated as $\mathrm{B}(\mathrm{R}), \mathrm{E}(\mathrm{R})$ and rainbreaks as $\mathrm{B}$ and $\mathrm{E}$ respectively.

3 days or longer, $52 \%$ are of 3 days duration, $27 \%$ of 4 days, $9 \%$ of 5 days duration. The composite patterns of the rainfall and the rainfall anomaly for active spells of duration 2 days or longer are shown in figure 10. It is interesting that the anomaly pattern of the active spells is diametrically opposite to that of the breaks, not only over the monsoon zone but also over the foot hills and eastern part of the southern peninsular.

Rainfall associated with relatively intense systems such as depressions or cyclonic storms is not well distributed over the monsoon zone. From the earliest studies (Eliot 1884) it has been known that the rainfall around the depression was usually heavy and continuous over a well defined area and beyond this area there was very little rain. The spatial extent of this area is about $1000 \mathrm{kms}$ along the track (Pisharoty and Asnani 1957). The daily rainfall in association with a depression exceeds even $10 \mathrm{cms}$ at a few stations (Sikka 1977). This would lead to the average rainfall of the zone within which the system lies (eastern or western) higher than 2 $3 \mathrm{cms}$. We take the intense spells to comprise days on which the average rainfall for the western zone 


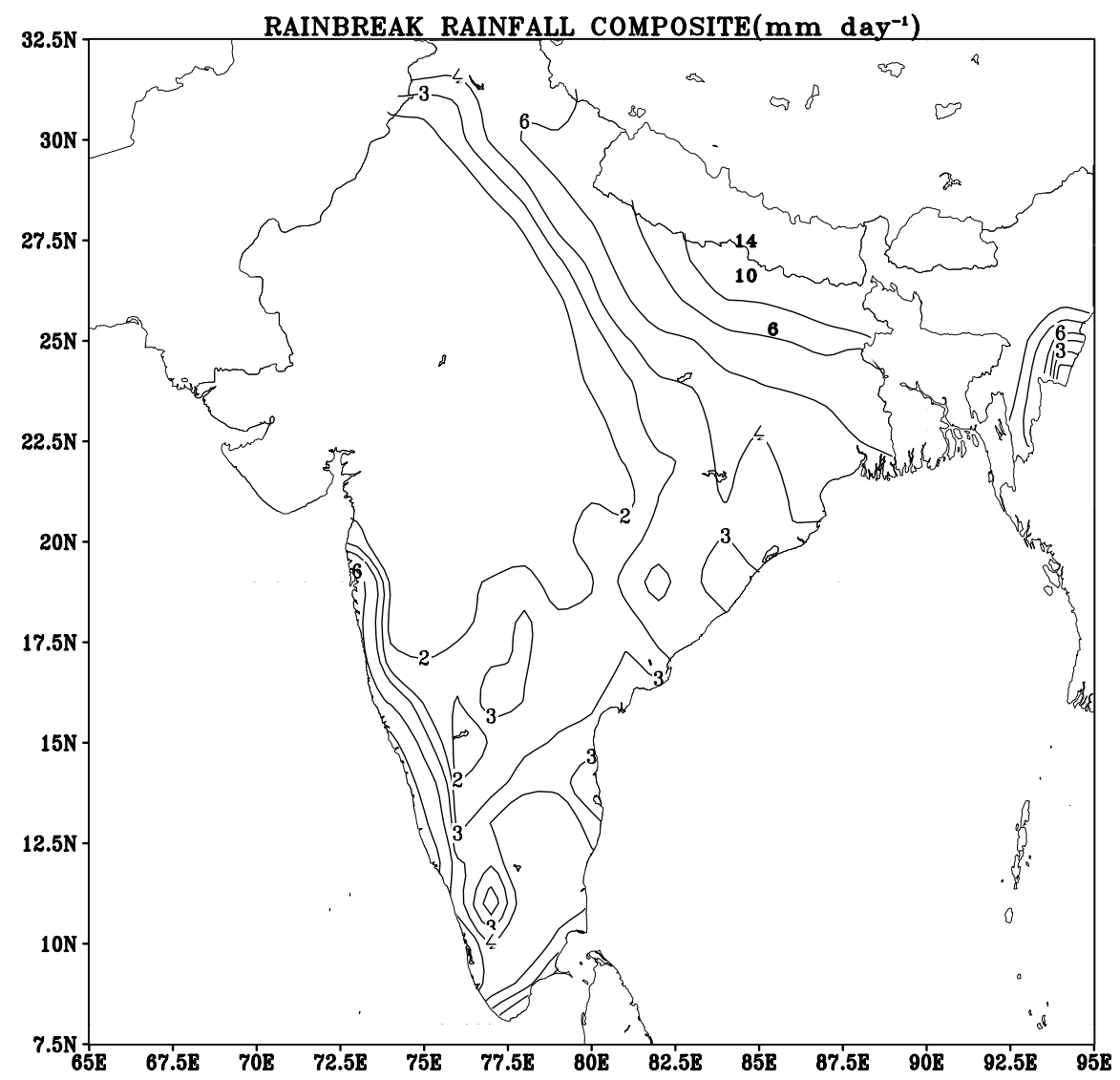

Figure 8(a). Composite of (a) rainfall and (b) rainfall anomaly for the rainbreaks during 1901-89 of three days or longer.

exceeds $20 \mathrm{mms}$ or that for the eastern zone exceeds $30 \mathrm{~mm} /$ day.

\subsection{Break days and all-India summer monsoon rainfall}

For the period 1901-89, the all-India summer monsoon rainfall (ISMR) from Parthasarathy et al (1994) versus the rainbreak days and for the period 1901-67, ISMR versus the number of R-break and D-break days is shown in figure 11(a). We find that the correlation with the Indian monsoon rainfall is negative and significant for rainbreak days as well as R-break-D-break days. The correlation is much higher with the number of rainbreak days (corr $=-0.56)$ than with the number of R-breakD-break days (corr $=-0.25)$.

While there is an association between larger number of break days and deficit monsoon, it is seen from figure 11(a) that the relationship is complex. Thus, out of fifteen years with deficit monsoon (ISMR $<90 \%$ average), in nine years the number of rainbreak days ranged from 16 to 24 ; whereas in the remaining six, the rainbreak days ranged from 6 to 9. In recent decades, during the deficit monsoons of 1974 and 1987 only six and eight rainbreak days occurred respectively. Out of eight years with excess monsoon (ISMR > $>110 \%$ of average) three had no breaks at all, in four the rainbreak days ranged from 3 to 8 while one (1933) had 14 rainbreak days. The monsoon season of 1933 (which also had eight R-break days) must have been exceptional in having active spells which more than compensated for the long break.

Also, for a given range of break days, there is a very large variation of rainfall. However, majority of the seasons (18 out of 22) with more than 10 rainbreak days are characterized with below normal all-India monsoon rainfall, with 10 of them having deficit of over $10 \%$. All the seasons with rainbreaks larger than 18 days are characterized by deficit in all-India rainfall being more than $10 \%$. The variation of ISMR with R-break days is high even for seasons with large number of such break days. For example, for the season with the largest number of R-break days, the ISMR is higher than average; out of seven seasons with more than 18 break days, above normal rainfall occurred in three.

\subsection{Active and intense spells and all-India rainfall}

The variation of ISMR with number of active and intense rainfall days is shown in figure $11(\mathrm{~b})$. It is 


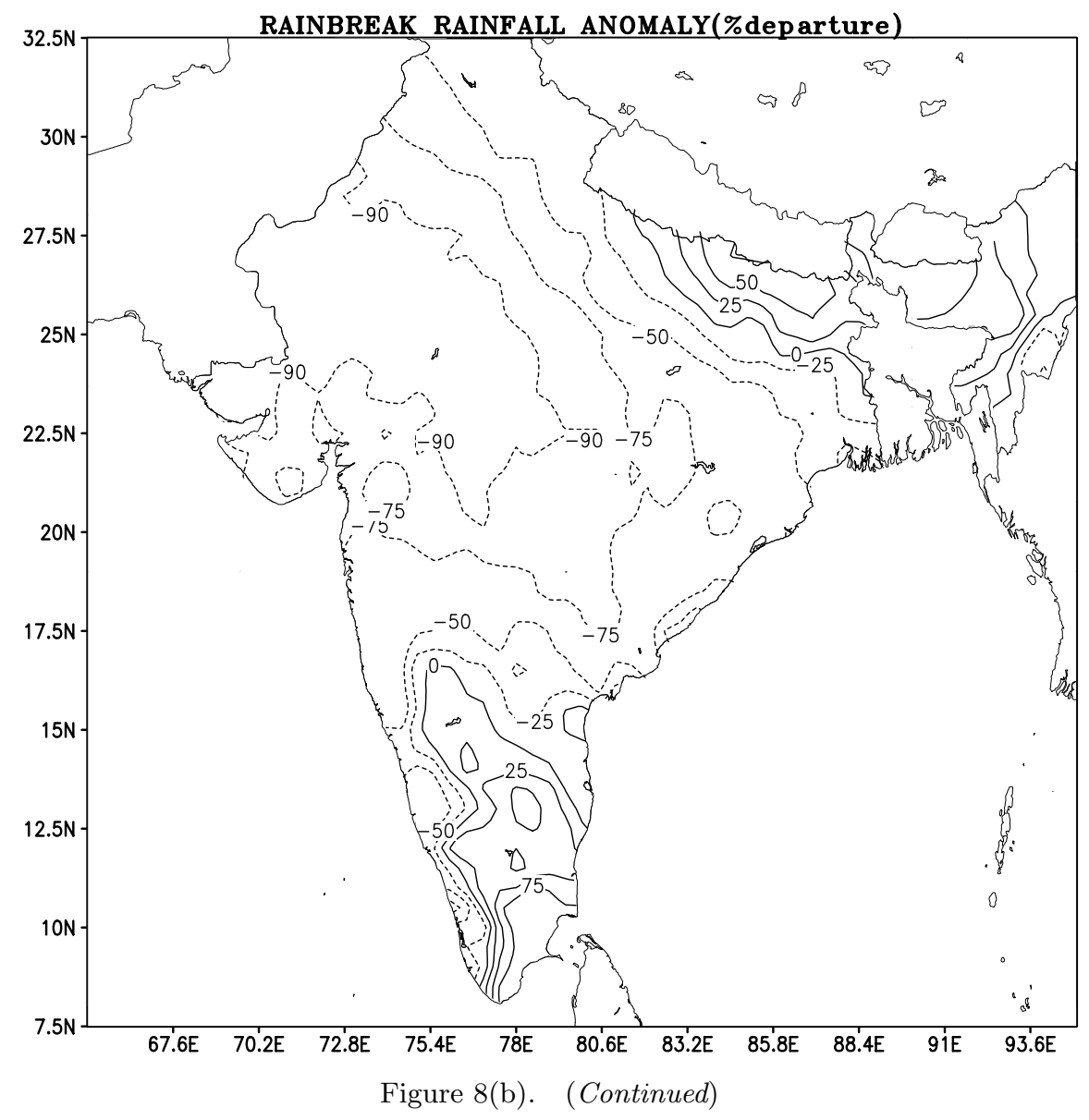

Table 4 .

\begin{tabular}{ccc}
\hline $\begin{array}{c}\text { Duration of } \\
\text { breaks (days) }\end{array}$ & $\begin{array}{c}\text { Rainbreaks } \\
\%\end{array}$ & $\begin{array}{c}\text { R-breaks } \\
\%\end{array}$ \\
\hline $3-4$ & 44.8 & 49.5 \\
$5-6$ & 22.8 & 19.8 \\
$7-8$ & 14.3 & 16.2 \\
$9-10$ & 6.7 & 6.3 \\
$11-12$ & 4.8 & 4.5 \\
$13-14$ & 3.8 & 1.0 \\
$>15$ & 2.8 & 2.7 \\
\hline
\end{tabular}

seen that the all India rainfall is positively correlated with the number of active days with well distributed rainfall over the monsoon zone. However ISMR is not related to the number of days with intense rainfall. This is consistent with Dhar et al (1980) result of lack of correlation of ISMR with the frequency of depressions and cyclonic storms.

\subsection{Active-weak cycles, breaks}

The number of breaks during the peak monsoon months of July-August varies from year to year in the range 0 to 3 during $1901-89$. We find that 24 years (27\%) had no breaks at all, 35 years $(39 \%)$ had one break, 23 years $(26 \%)$ had two breaks and 7 years $(8 \%)$ had three breaks. Thus the break is a special event which does not occur in every season. When more than one break occurs in a season (34\% of the years) the interval between the two breaks varies between 2 days and 55 days. The probability of this interval being less than ten days is almost $50 \%$. Hence it does not seem appropriate to describe the fluctuations of monsoon rainfall between active and weak spells observed every season, as active break cycles.

\section{Rainfall, OLR and circulation patterns of the rainbreaks and active spells of the monsoon}

We have analysed the circulation patterns for all rainbreaks of duration longer than five days and all the active spells of duration longer than three days during 1972-89 (tables 5 and 6). The OLR patterns have also been analysed for such breaks and active spells after 1974. Anomalies have been derived by subtracting the July-August climatology from the patterns for the breaks. It should be noted that rainfall data for a specific day such as 20th July is the accumulated rainfall for the 24 hours ending 


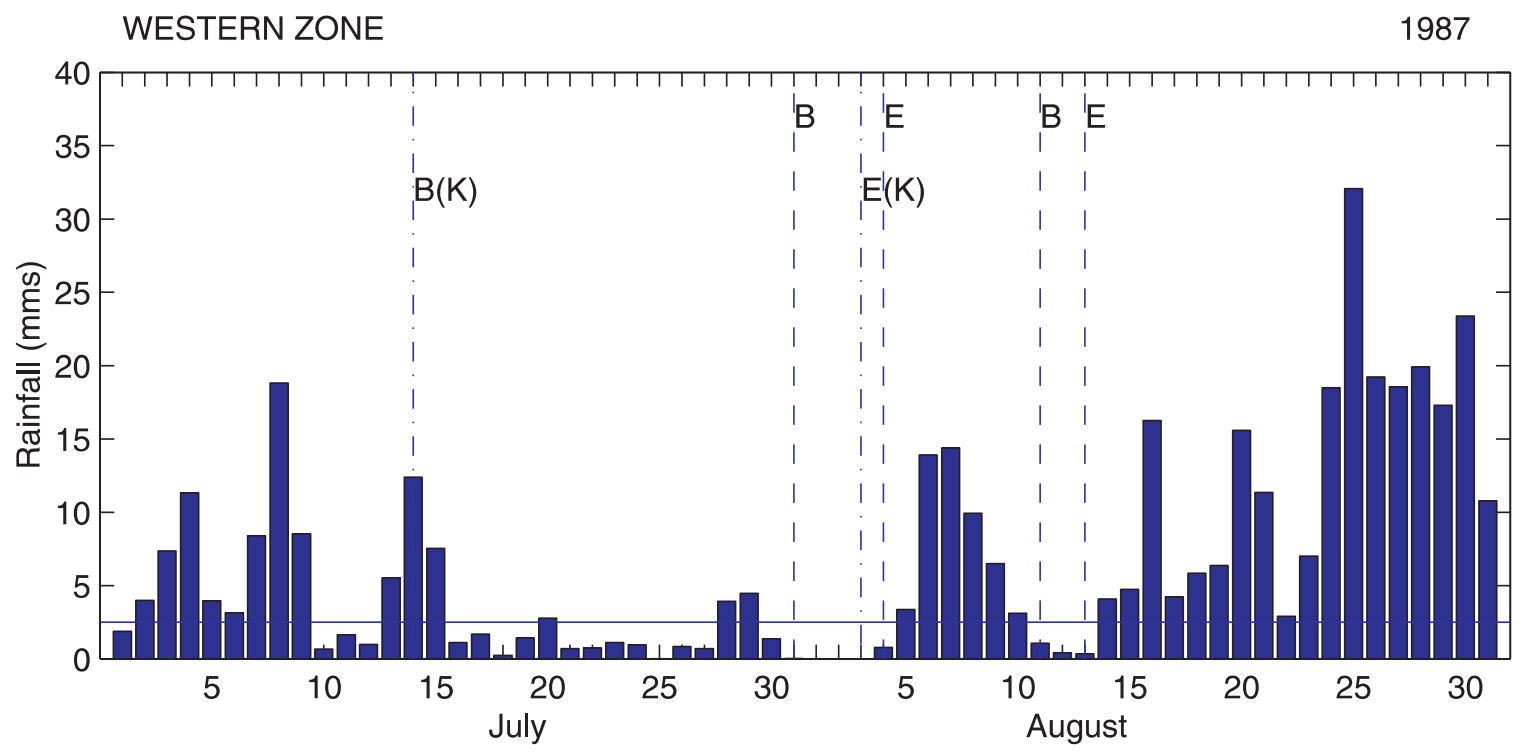

EASTERN ZONE

1987
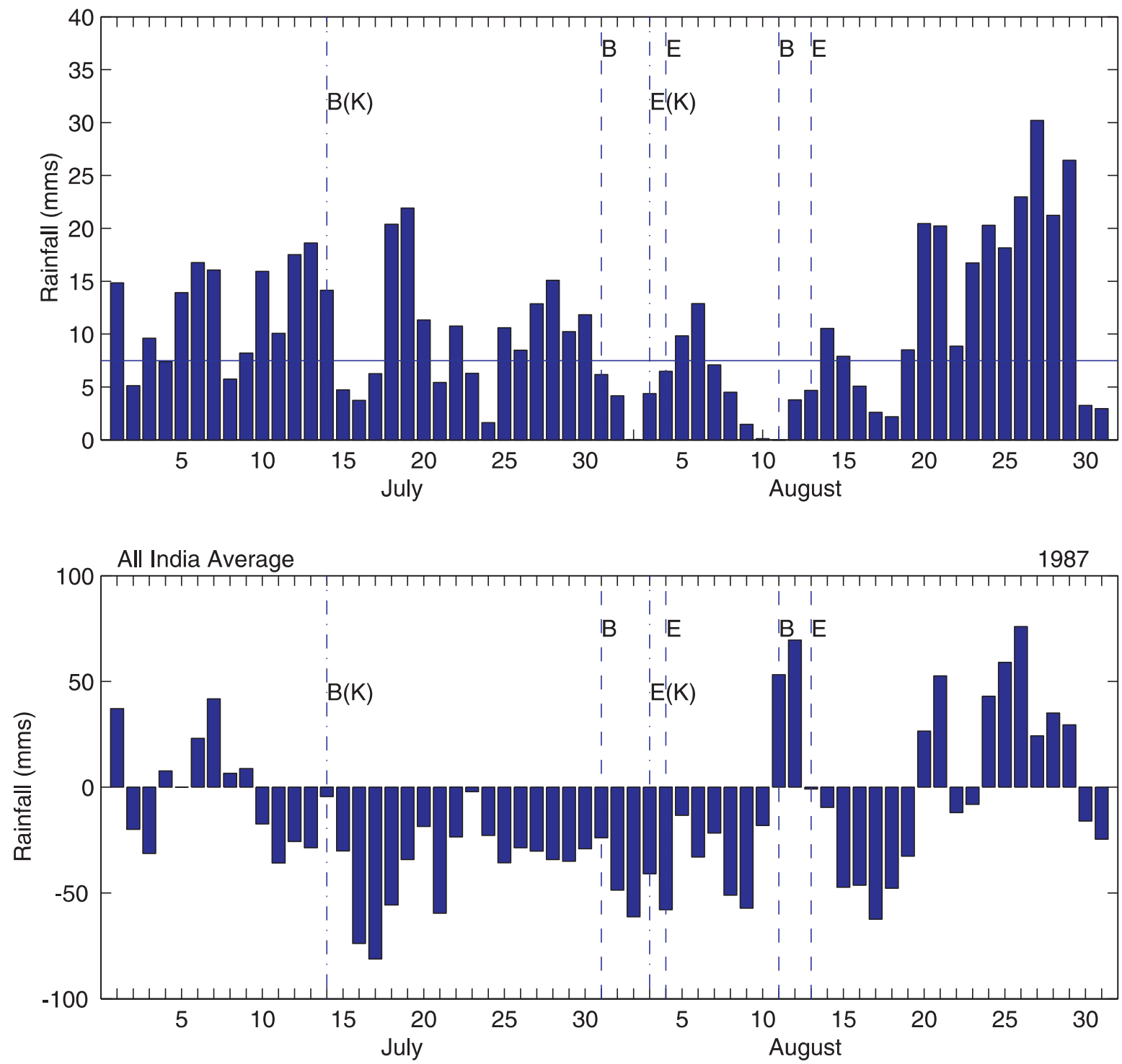

Figure 9. Average daily rainfall over western and eastern zones during July and August 1987. The beginning and end of rainbreaks by $\mathrm{B}$ and $\mathrm{E}$ and of those identified by Krishnan et al (2000) are indicated by B(K) and E(K) respectively. 


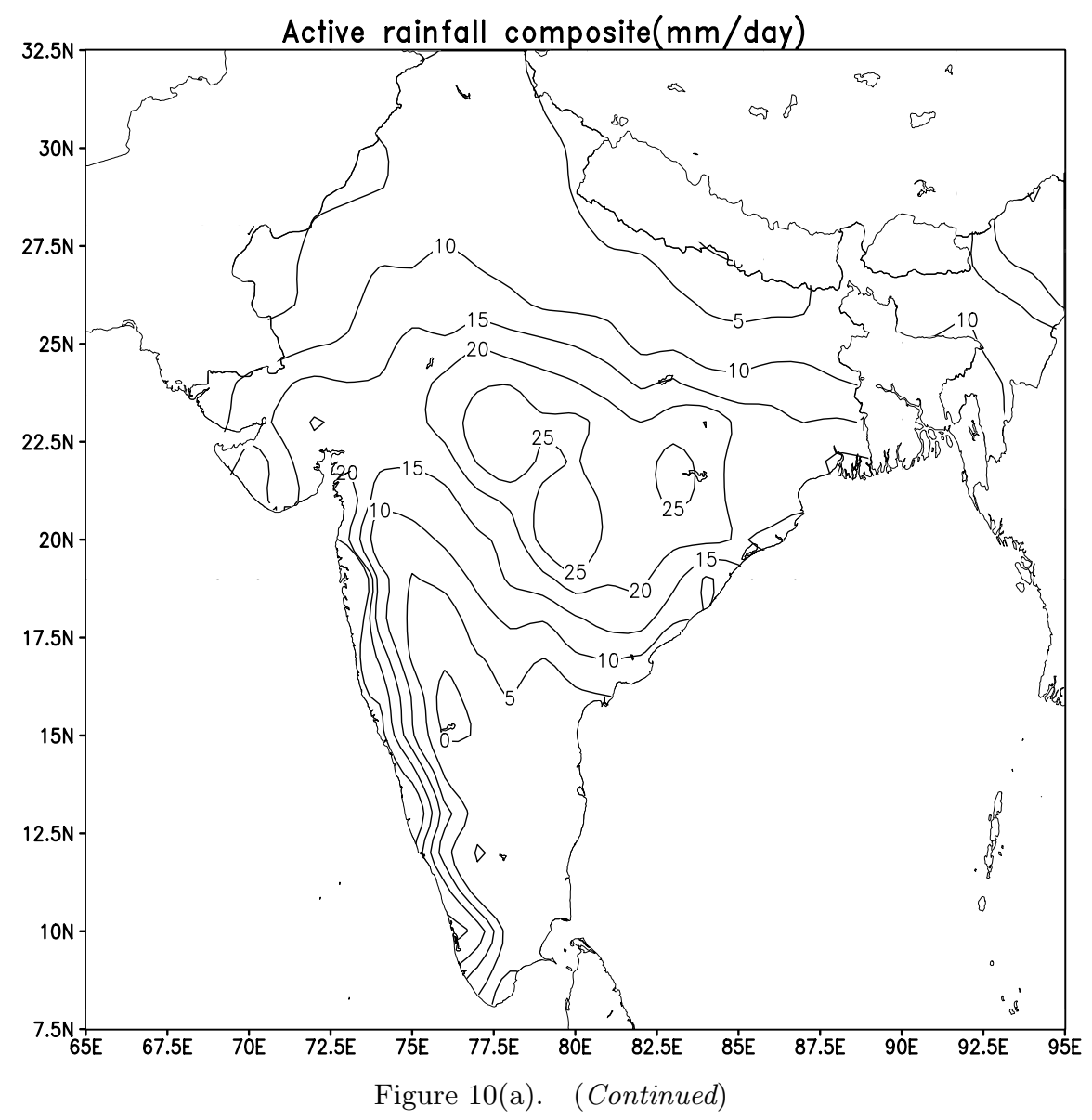

at $8.30 \mathrm{am}$ on 20 th July. Hence the circulation and OLR data corresponding to a given day for rainfall data is the previous day i.e., 19th July in this case.

\subsection{OLR patterns}

The OLR and OLR anomaly patterns (with respect to the July-August mean) for the rainbreak and active composites are shown in figure 12(a) and the OLR anomaly patterns for the individual rainbreaks in figure 12(b). It is seen from figure 12 that the OLR anomalies are positive and larger than $30 \mathrm{Wm}^{-2}$ over most of the Indian monsoon zone and positive over almost the entire Indian region in the rainbreak composite as well as for each of these rainbreaks. The maximum anomaly of little over $50 \mathrm{Wm}^{-2}$ in the composite, occurs westward of $80^{\circ} \mathrm{E}$ in the monsoon zone. The OLR is higher than $240 \mathrm{Wm}^{-2}$ over a large part of the Indian monsoon zone. Over the equatorial region of the Indian longitudes, large negative anomalies are seen in the patterns of the composite as well as individual rainbreaks (figure 12a, b), indicating an active phase of the oceanic TCZ. In the composite active OLR anomaly pattern (figure 12a), there are large negative anomalies over the monsoon zone and positive anomalies (with OLR $>225 \mathrm{Wm}^{-2}$ ) over the equatorial region between $70^{\circ}$ and $90^{\circ} \mathrm{E}$. Thus the active phase (rainbreak) corresponds to an active (weak) phase of the continental TCZ and weak (active) phase of the oceanic TCZ over the equatorial region. This is a manifestation of the competition between the oceanic TCZ and the continental TCZ suggested by earlier studies (Sikka and Gadgil 1980). Hence, over the Indian longitudes, the OLR anomaly patterns for active spells and rainbreaks, comprise a north-south dipole with the sign for the active composite being opposite to that for the rainbreak composite.

Over the tropical W. Pacific north of $20^{\circ} \mathrm{N}$, the rainbreak (active) composite is characterized by large negative (positive) anomalies (figure 12). Thus over this latitudinal belt the anomaly pattern comprises an east-west dipole. The rainbreak composite over the west Pacific is characterized by positive anomalies south of about $15^{\circ} \mathrm{N}$ (figure 12a). In the active composite, there is a convective zone (with negative OLR anomalies) across the west Pacific, which is almost continuous with that over the Indian longitudes. Comparison of the active and rainbreak composite OLR patterns suggests that the TCZ over the west Pacific during the rainbreak is weaker and located northward relative to that of the active phase. It is seen that 


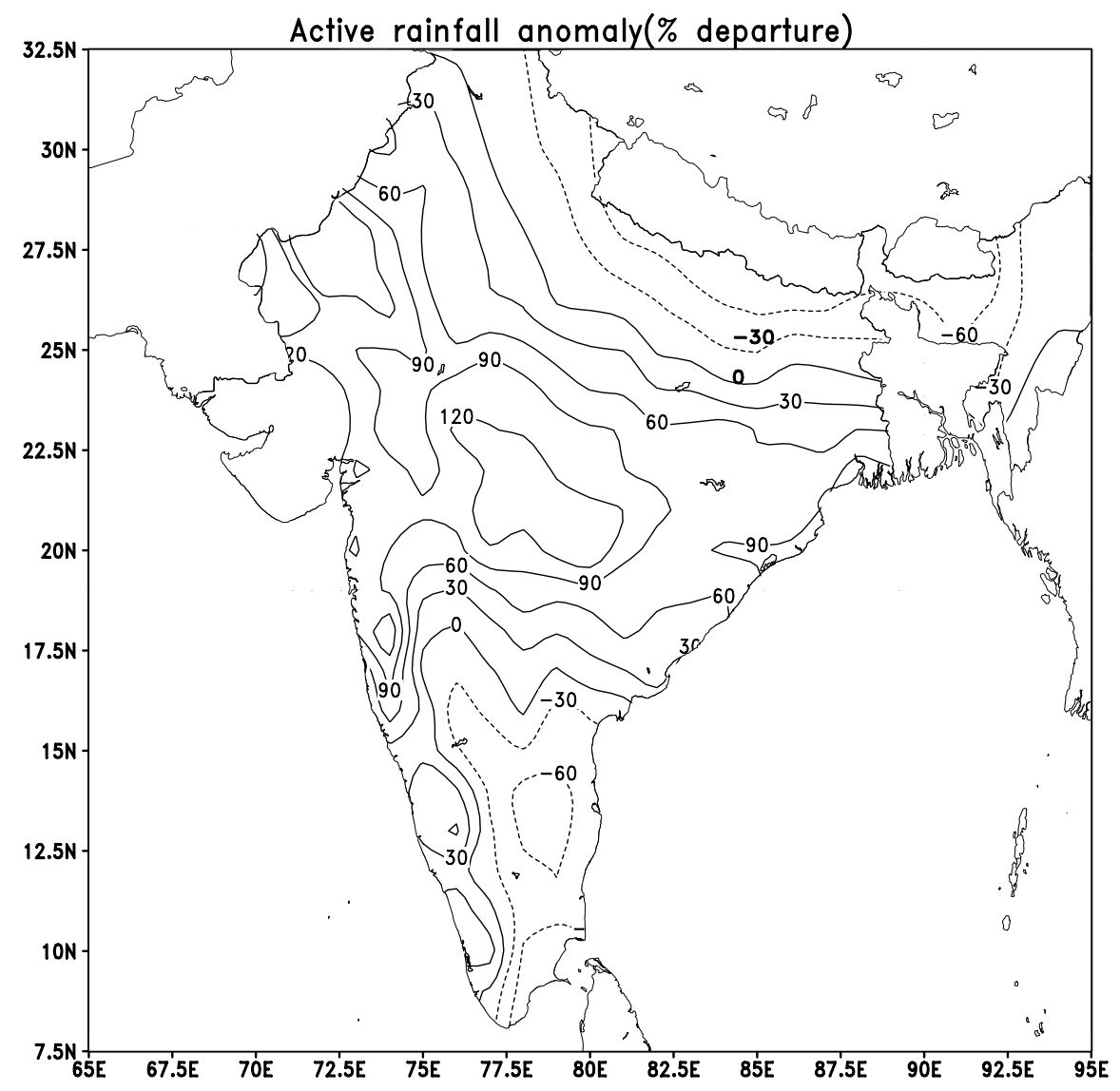

Figure 10(b). Composite of (a) rainfall and (b) rainfall anomaly for the active spells during 1901-89.

the anomaly pattern of the rainbreak composite over the west Pacific comprises a dipole which is in opposite phase to the north-south dipole over the Indian region implying a quadrapole over the AsiaW. Pacific region. However, in the active composite, the anomalies are positive over the belt equatorward of the convective zone across the Asia west Pacific region i.e., the anomalies over the equatorial regions of the west Pacific are similar to those in the rainbreak. Thus the OLR anomaly pattern for an active spell corresponds to a dipole over the Asia W. Pacific region rather than a quadrapole as in the rainbreak. Hence, over the equatorial region of the west Pacific, the pattern for the active spell is not diametrically opposite to that characterizing a rainbreak. Since the pattern of the rainbreak composite is opposite to that of active composite over the Indian longitudes, the signal can be enhanced by considering patterns of active minus break spells over the Indian region. However, patterns over the W. Pacific associated with active minus break spells cannot be considered as meaningful.

The correlation of the three-day running mean of the OLR over the tropical belt with that of the OLR of the monsoon zone is shown in figure 12(c).
The correlation with OLR of the monsoon zone is negative over the equatorial Indian Ocean as well as the northern part of the tropical west Pacific $\left(20^{\circ}\right.$ to $\left.30^{\circ} \mathrm{N}\right)$. The negative (positive) anomalies seen over these regions in the OLR anomaly patterns for rainbreaks (active spells) are consistent with this correlation pattern.

A feature which is seen in the OLR anomaly pattern for the rainbreak composite (figure 12a), as well as for each of the individual rainbreaks (figure $12 \mathrm{~b}$ ) is a region of negative OLR anomaly over the eastern Pacific between $10^{\circ}$ and $20^{\circ} \mathrm{N}$. In the active composite, positive anomalies are seen over this region. This is consistent with the correlation of the OLR of this region with the OLR of the monsoon zone in figure 12(c). What happens over the Indian monsoon zone appears to be linked to the E. Pacific not only on the interannual scale (as evinced by the link between the El Nino and the monsoon) but on the intraseasonal scale as well.

Next, we compare the OLR/precipitation patterns associated with active spells and rainbreaks with those associated with breaks defined by different criteria in the recent studies. As expected, there are differences in the OLR anomaly pat- 

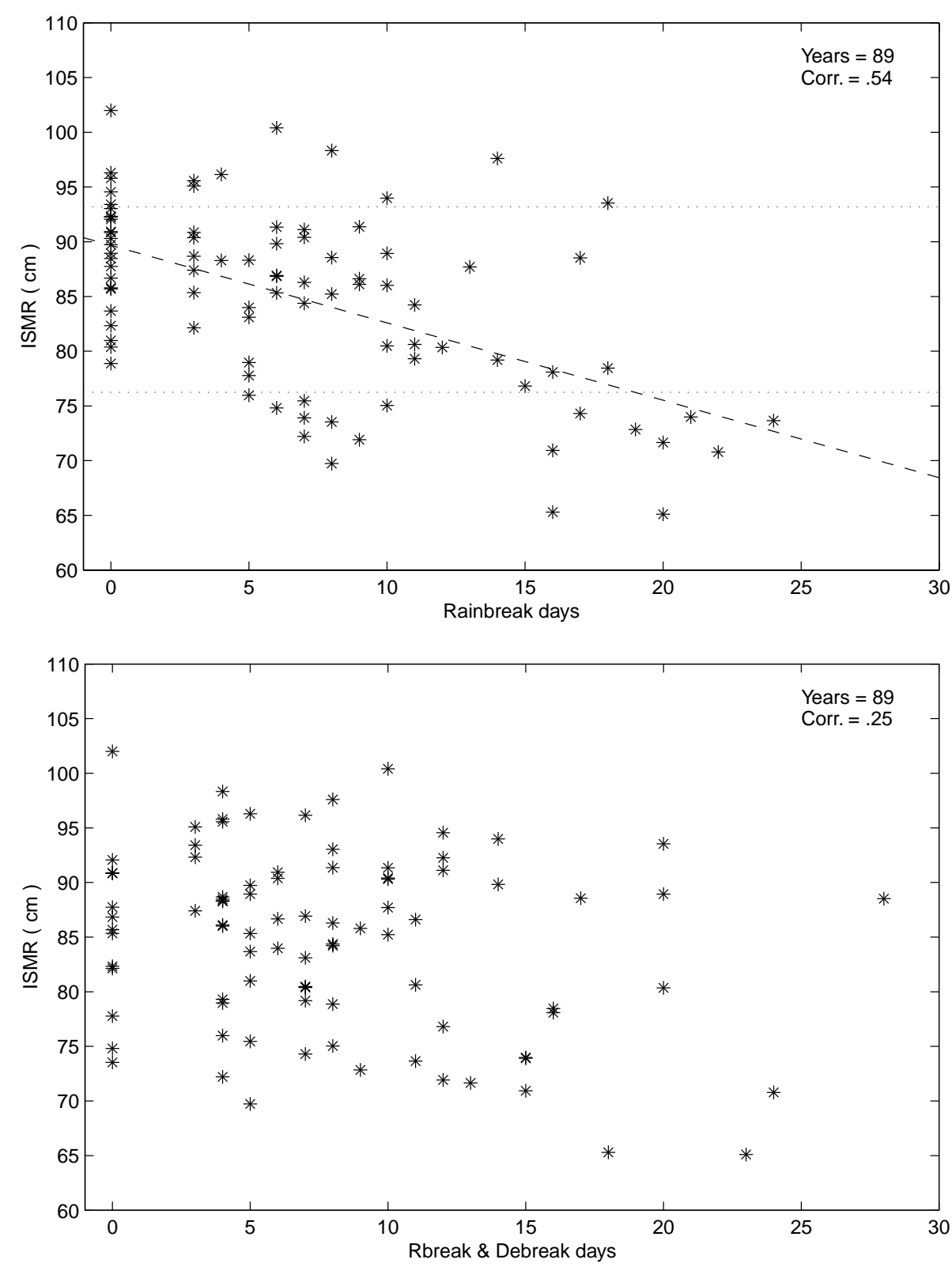

Figure 11(a). All-India summer monsoon rainfall (ISMR) versus rainbreak days (above) and R-break days (below).

terns over the Indian region and the surrounding seas. The active minus break precipitation anomaly pattern in the $\mathrm{W}$ study has a maximum over the Indian region around $10^{\circ} \mathrm{N}$ over the peninsula southward of the Indian monsoon zone. There are positive OLR anomalies over the monsoon zone for $\mathrm{K}$ breaks, with the maximum anomalies of about $38 \mathrm{Wm}^{-2}$ over the western part of the monsoon zone i.e., in the region $75^{\circ}-80^{\circ} \mathrm{E}$ and $20^{\circ}-28^{\circ} \mathrm{N}$. For the AS active minus break patterns for the 40 (15) day mode also there are negative anomalies over the monsoon zone with the maximum of a little over $20 \mathrm{Wm}^{-2}\left(6 \mathrm{Wm}^{-2}\right)$ over the western part. Thus although the $\mathrm{K}$ break and AS active minus break are characterized by the largest anom- alies over the monsoon zone, the magnitude of the maximum anomaly of the rainbreak composite (figure 12a) is higher than that of $\mathrm{K}$ breaks and more than twice that of the AS. The active break anomaly patterns of the GM study differ markedly from these in having maximum anomalies over the head of the Bay of Bengal and a coherent band of positive (negative anomalies in breaks (active spells) from the Indian monsoon zone onto the west Pacific at least up to $140^{\circ} \mathrm{E}$.

In spite of the differences in the spatial patterns of the anomalies over the Indian region, the northsouth dipole over the Indian longitudes is seen in the OLR composites of K-breaks, the 40 day mode breaks of GM as well as the active minus break 

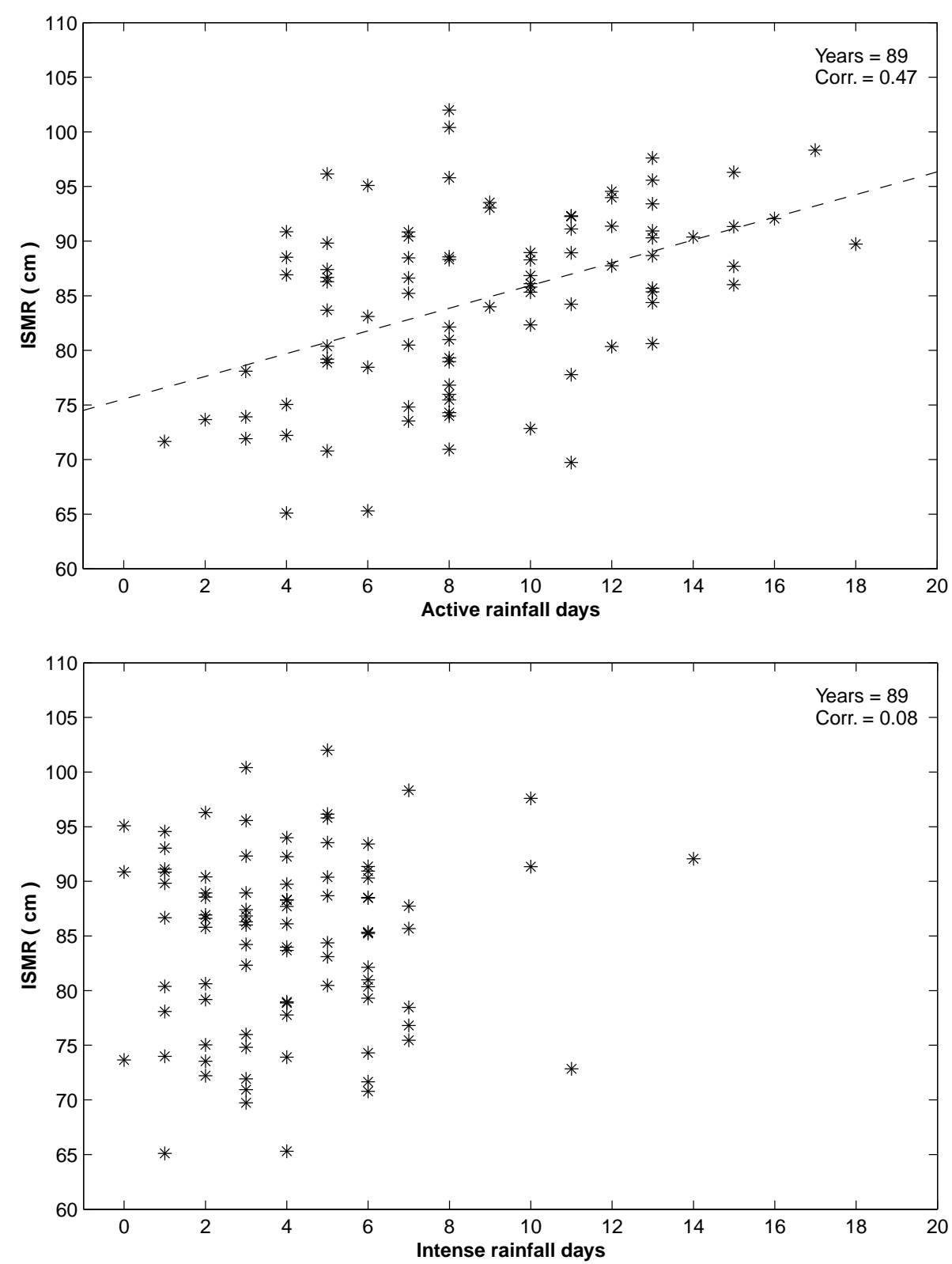

Figure 11(b). All India monsoon rainfall (ISMR) versus number of active rainfall days (above) number of intense rainfall days (below).

composites for the W study and 40 day mode of AS and to some extent (around $90^{\circ} \mathrm{E}$ ) in the OLR anomaly pattern associated with the 15 day mode of AS. Thus this appears to be a basic feature of the weak phase of the intraseasonal variation. In all these patterns (with the exception of that in the GM study and the 15 day mode of AS) an anomaly of the opposite sign (same sign) to that over the Indian region occurs over the northern (equatorial) part of the tropical west Pacific leading to the quadrapole over the Asia W. Pacific region. Since AS and $\mathrm{W}$ present only the active minus break composites, it is not clear whether the quadrapole is a feature only of the break as suggested by figure 12(a), or also of the active composite. Since the
OLR composites of breaks/active minus breaks in other studies are presented only westward of about $150^{\circ} \mathrm{E}$, it is not possible to ascertain whether over the east Pacific between $10^{\circ}$ and $20^{\circ} \mathrm{N}$ (figure 12) anomalies of a sign opposite to that over the Indian region occur. However, the wind anomalies corresponding to the 40 day mode of AS are consistent with the presence of such OLR anomalies in their active minus break pattern.

The rainbreaks are associated with larger anomalies than the breaks studied by K and AS (40 day mode) over the Indian region and there are also differences in the patterns of the anomalies. Yet, the anomaly patterns associated with rainbreaks over the equatorial Indian Ocean and the Pacific appear 
Table 5. Rainbreaks longer than five days during 1972-89.

\begin{tabular}{ll}
\hline 1972 & 19th July - 3rd August \\
1979 & 15th -31 st August \\
1981 & 24th -31 st August \\
1982 & 1st -8 th July \\
1986 & 22 nd -31 st August \\
\hline
\end{tabular}

Table 6. Active spells of 4 days and longer duration during 1972-89.

\begin{tabular}{ll}
\hline 1973 & 17 th -21 st July \\
1975 & 11 th -14 th August \\
1979 & 6 th -10 th August \\
1982 & 17th -22 nd August \\
1986 & 23rd -29 th August \\
\hline
\end{tabular}

to be similar to those of the K and AS breaks; however the magnitude of the anomalies is larger.

\subsection{Circulation patterns}

The active and rainbreak composite patterns for wind vectors at 850 and $200 \mathrm{hPa}$ and composite anomaly patterns for zonal wind at $850 \mathrm{hPa}$ are shown in figure 13 . We find that the Ramamurthy (1969) and the IMD criterion for breaks viz., westerlies over the entire Indian region with no easterlies to the north of the normal position of the monsoon trough is satisfied from the surface up to $700 \mathrm{hPa}$. At $850 \mathrm{hPa}$, strong westerly anomalies are seen north of $20^{\circ} \mathrm{N}$ over the Indian region for each of the breaks. In the active anomaly composite, at $850 \mathrm{hPa}$ over the Indian region, westerly anomaly occurs south of $20^{\circ} \mathrm{N}$ and strong easterly anomaly to the north implying a large cyclonic vorticity anomaly. Large cyclonic vorticity (and anomaly) is also present over the W. Pacific in the region of low OLR. It is seen from figure 13(a) that in the rainbreak composite, the axis of the low level jet stream at $850 \mathrm{hPa}$ (Joseph and Raman 1966; Findlater $1969)$ over the Indian longitudes $\left(70^{\circ}-90^{\circ} \mathrm{E}\right)$ shifts southward to about $5^{\circ} \mathrm{N}$, strengthens over the $\mathrm{W}$. Pacific and extends further eastward. The cyclonic vorticity in the equatorial region is enhanced by this shift of the axis of the low level jet. Over the west Pacific, the cyclonic vorticity north of $10^{\circ} \mathrm{N}$ is enhanced with the strengthening of westerlies.

Note that the rainbreak anomaly pattern of the zonal wind at $850 \mathrm{hPa}$ (figure 13b) comprises a quadrapole similar to that seen in the OLR pattern. The active composite anomaly pattern of the zonal wind at $850 \mathrm{hPa}$ is again more like a dipole (as in the case of the active composite OLR pattern) rather than the quadrapole characterizing the break composite.
In the rainbreak composite, there is a strong cyclonic circulation over large parts of the region $110^{\circ}-140^{\circ} \mathrm{E}, 10^{\circ}-30^{\circ} \mathrm{N}$. This anomaly of cyclonic circulation over the west Pacific, which is associated with a negative OLR anomaly over the region is clearly seen in the mean winds of each of the break periods as well. The other important features of the lower tropospheric circulation in the rainbreak anomaly pattern are

- easterlies over the Indian region south of about $20^{\circ} \mathrm{N}$

- westerlies over the equatorial region east of about $65^{\circ} \mathrm{E}$ and

- northerlies over the Bay of Bengal.

Most of these features are also seen in the Kbreak composite and active minus break patterns of AS and W studies. However, the strong southerlies over $140^{\circ}-150^{\circ} \mathrm{E}$ characterizing K-breaks (their figure 2c) are not seen in figure 13.

Several earlier studies suggest a decrease (increase) in the cross-equatorial flow west of $60^{\circ} \mathrm{E}$ in the breaks (active minus break). This is also seen in the composite rainbreak pattern. There is also a marked increase in the cross equatorial flow between $100^{\circ}$ and $130^{\circ} \mathrm{E}$ into the region of cyclonic vorticity anomaly over the W. Pacific and also around $150^{\circ} \mathrm{E}$. However, we find that there is some variation in the anomaly patterns of crossequatorial flow for different breaks. Thus it is negative for the breaks in 1972, 1979 and 1986 but is large only in the last case. For the breaks of 1981 and 1982 the anomaly is very small and positive over parts of the region. Thus it cannot be considered to be a robust feature of the rainbreak.

In the upper troposphere, the prominent feature of the break composite is a wave with the central latitude around $40^{\circ} \mathrm{N}$ (figure 13). There are southerlies over the Indian longitudes $\left(70^{\circ}-90^{\circ} \mathrm{E}\right)$ flanked by northerlies on either side. This pattern is very similar to the Asia-Pacific wave of Joseph and Srinivasan (1999) with the same phase as that in May prior to deficit monsoon years. Beginning with Ramaswamy (1962) Indian meteorologists had associated breaks with intrusion of a deep trough in the mid-latitude westerlies into India in the upper troposphere and the consequent shift of the Tibetan anticyclone eastwards. Such a trough in the mid-latitude westerlies is seen around the longitude of about $65^{\circ} \mathrm{E}$ from $25^{\circ} \mathrm{N}$ to $55^{\circ} \mathrm{N}$. This wave is absent in the active composite.

\subsection{Implications}

Thus, a quadrapole over the Asia-west Pacific region arising from anomalies opposite (same) in sign to those over the Indian region occurring over the equatorial Indian Ocean and northern tropical (equatorial) parts of the west Pacific is seen in 


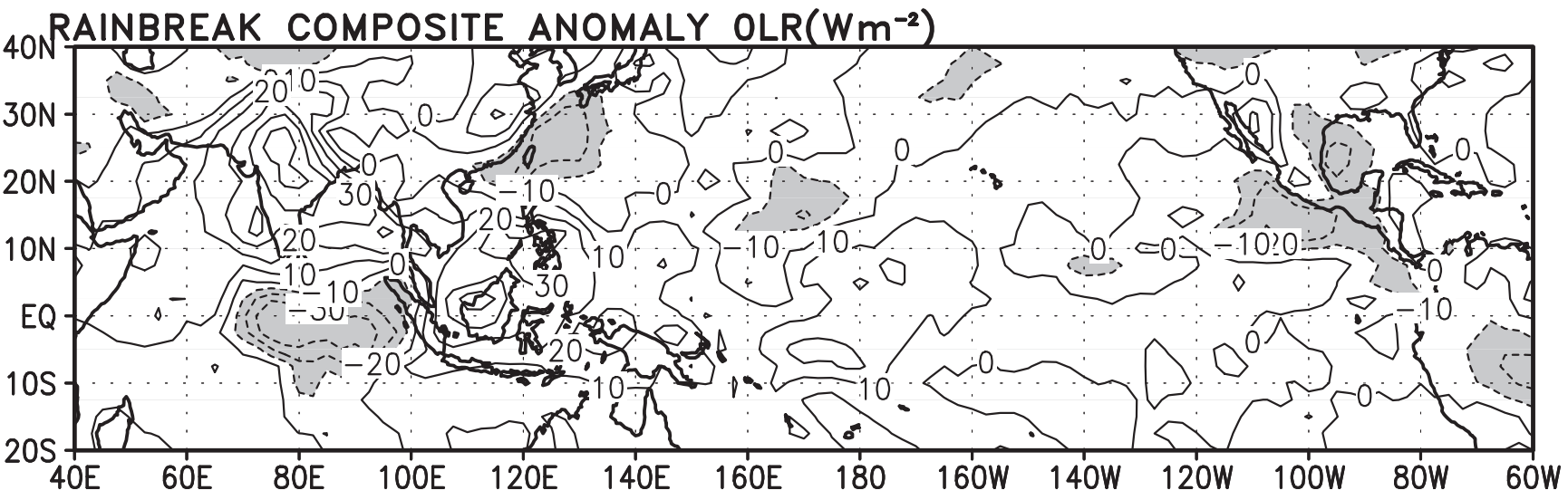

40N RAINBREAK COMPOSITE OLR $\left(\mathrm{Wm}^{-2}\right)$
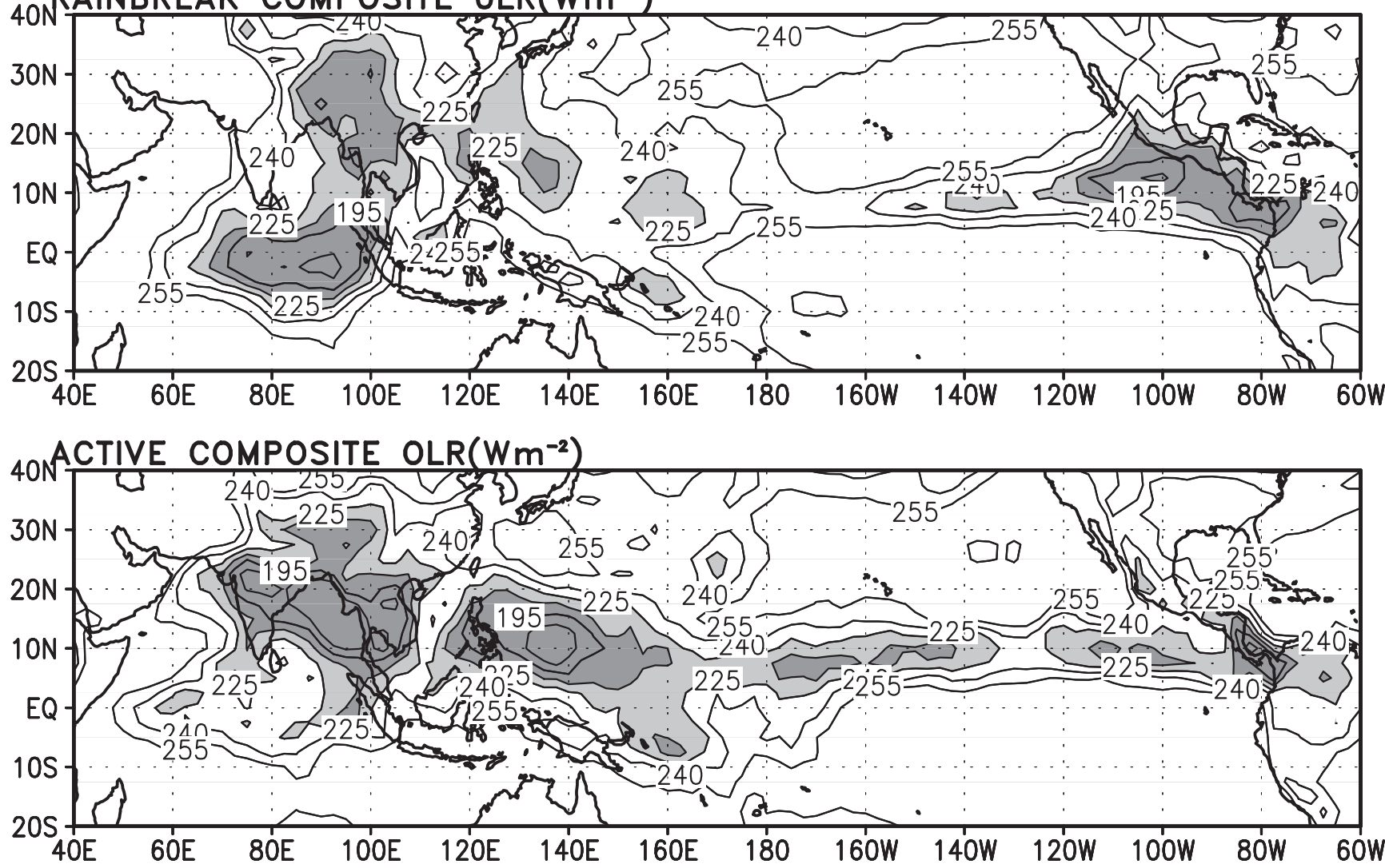

4ONACTIVE COMPOSITE ANOMALY OLR $\left(\mathrm{Wm}^{-2}\right)$

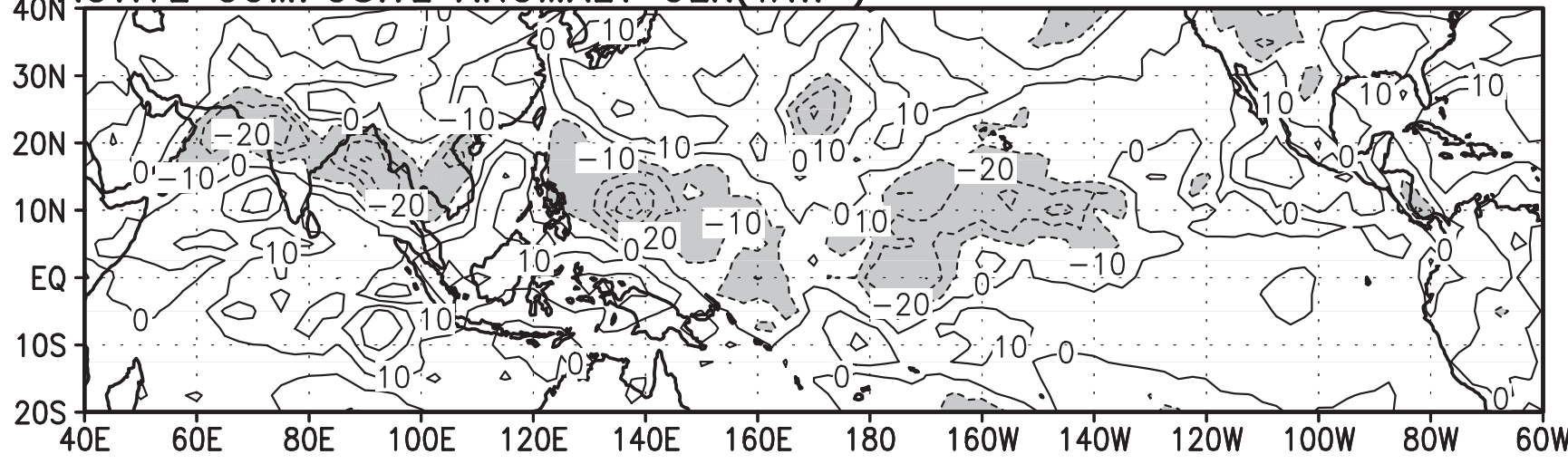

Figure 12(a). OLR and OLR anomaly patterns for rainbreak composite and active composite. 


\section{RAINBREAK OLR ANOMALY PATTERNS}
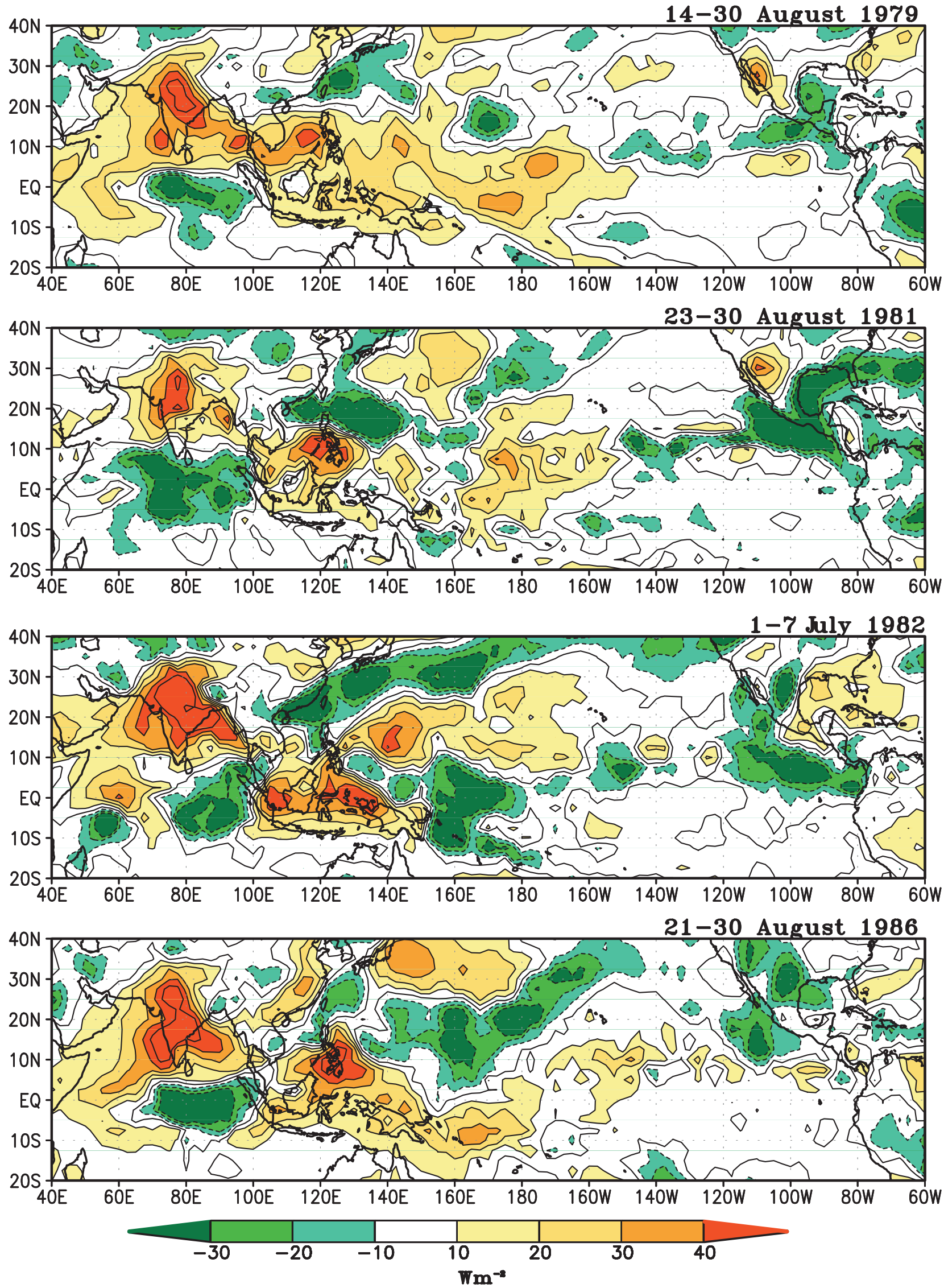

Figure 12(b). OLR anomaly patterns for each of the four long breaks. 
OLR CORRELATION WITH OLR OF MONSOON ZONE

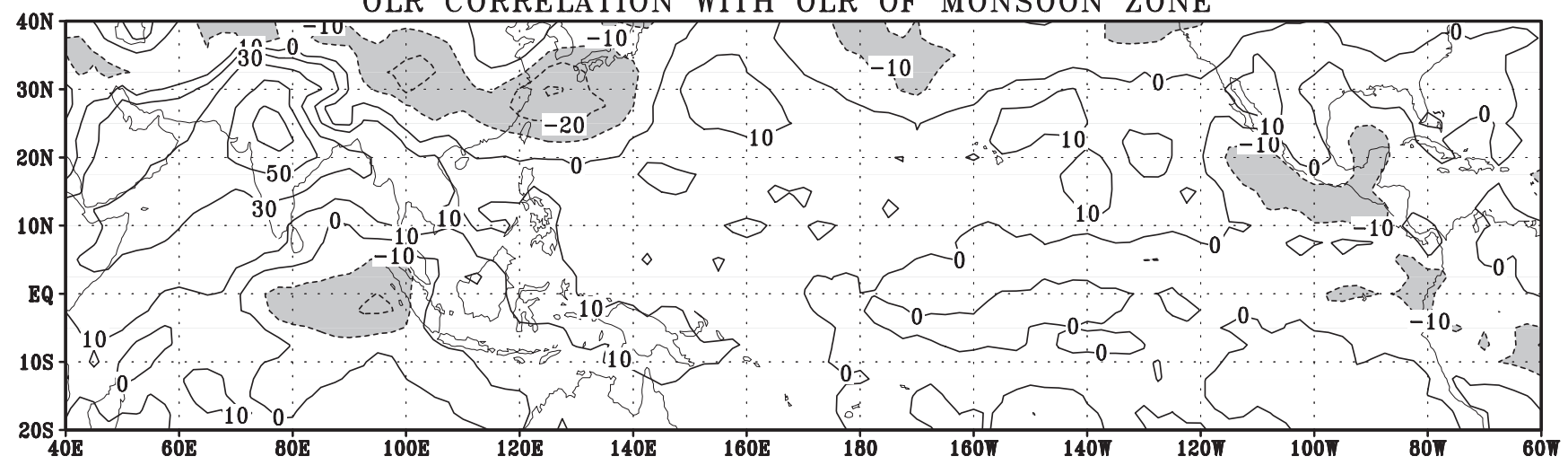

Figure 12(c). OLR correlation with OLR of the monsoon zone.

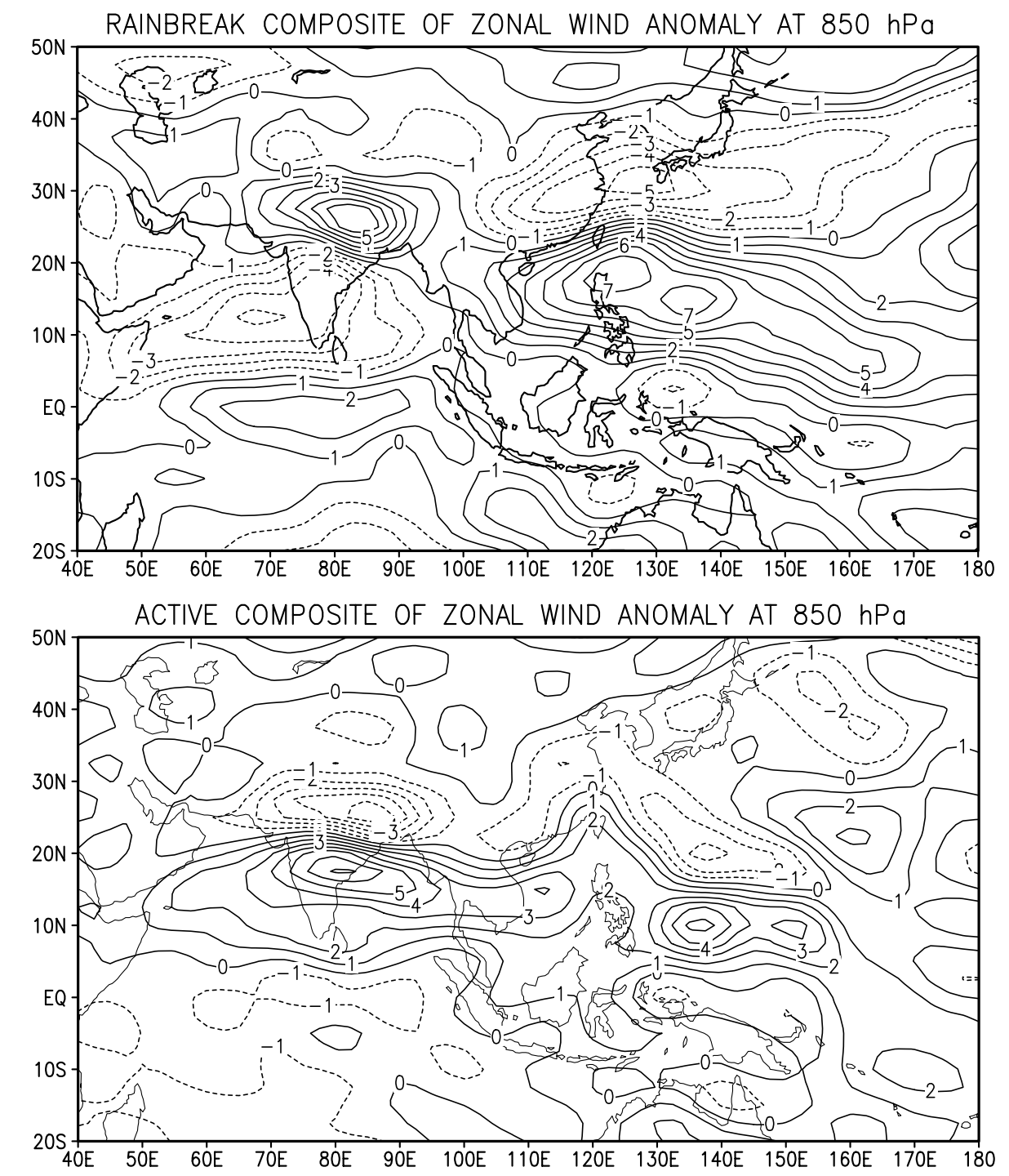

Figure 13(a). 850 hpa zonal velocity anomaly: break composite (top), active composite (below). 


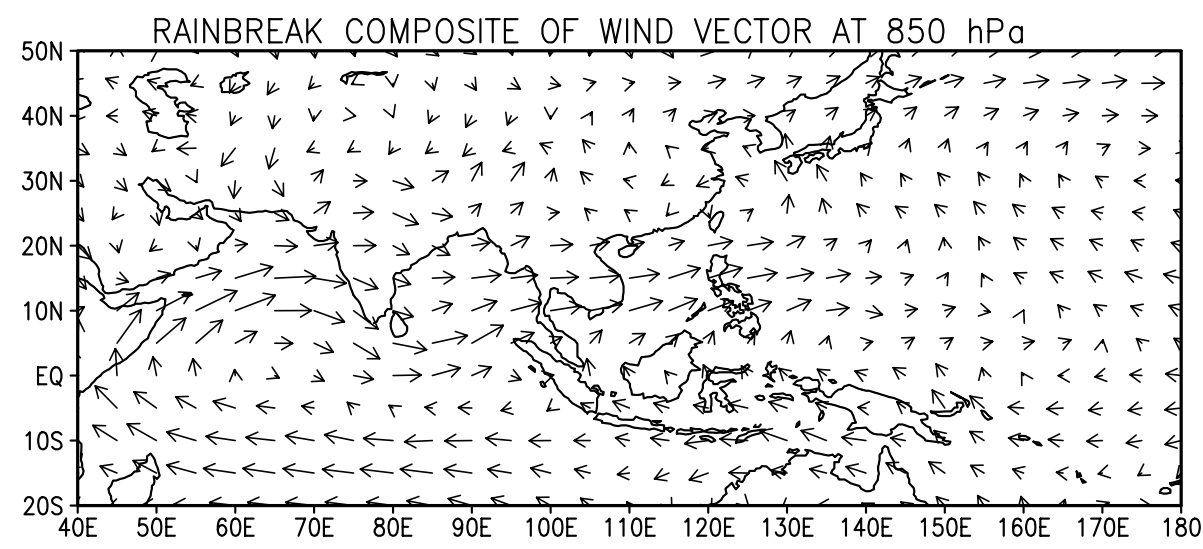

$\overrightarrow{10}$

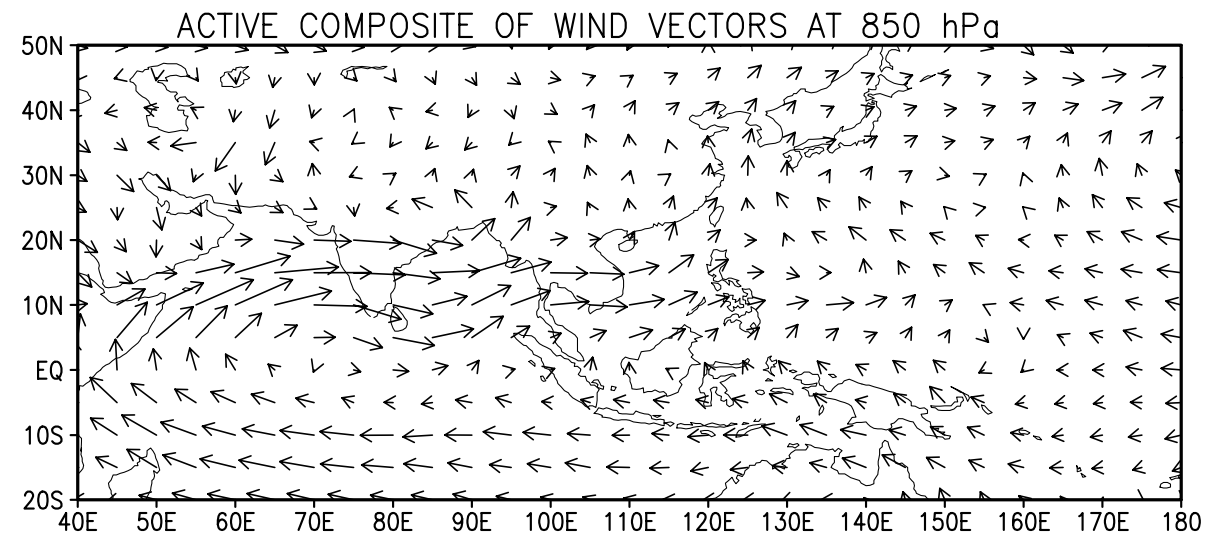

$\overrightarrow{10}$

Figure 13(b). 850 hpa wind vector: break composite (top), active composite (bottom).

breaks identified on the basis of different criteria as well as the rainbreaks identified in this paper.

This feature appears to be independent of the detailed distribution of convection/precipitation anomalies over the Indian region. As discussed in section 3.3, there are three or four active-break cycles in a season according to Webster et al (1998) which implies a time scale of about 40 days. For this time scale, GM (AS) have studied the patterns associated with active spells and breaks (active minus break). On the other hand, neither the traditional breaks (R-breaks, D-breaks) nor the rainbreaks occur every year. We have also noted that the magnitude of the anomalies is higher for the rainbreaks. All this suggests that the 'breaks' in these studies are weak spells of the intraseasonal variation of the monsoon, which occur every year. The quadrapole is thus, a basic feature of weak spells. Since the traditional breaks and rainbreaks are intense weak spells, this basic feature is also seen in the composite patterns of these breaks.

Clearly, a realistic simulation of this feature by a model is a prerequisite for using the model for understanding the intraseasonal variation of the Asia-W Pacific region. However, for understanding the phenomenon of breaks in the monsoon studied for several decades, or rainbreaks, the model must also simulate realistically the rainfall pattern over the Indian region associated with these breaks and the special features of the circulation associated with long breaks. Studies with such models and analysis of observations are required to elucidate the cause-effect relationships of the links with convection over the equatorial Indian Ocean and the west and east Pacific Ocean and also the relationship of the anomalies of convection over these oceanic regions to the SST field.

\section{Summary and conclusions}

For over a century, the term 'break' has been used for spells in which the rainfall over the Indian monsoon zone is interrupted. The phenomenon of 'break monsoon' is of great interest because long intense breaks are often associated with monsoon 


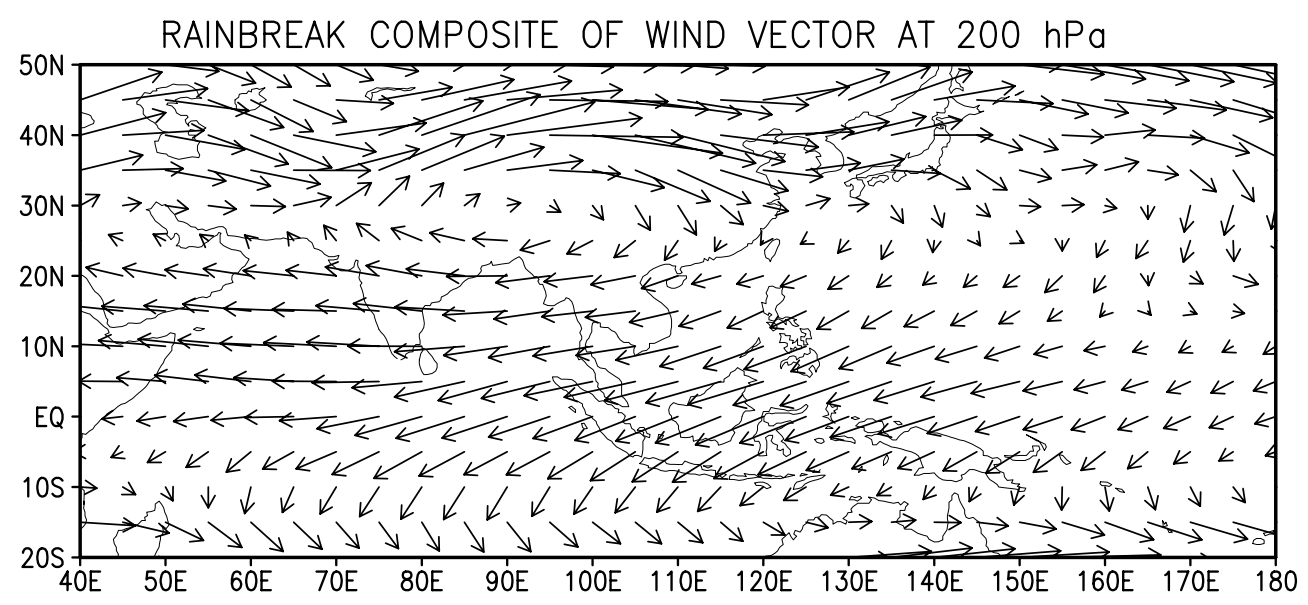

$\overrightarrow{10}$

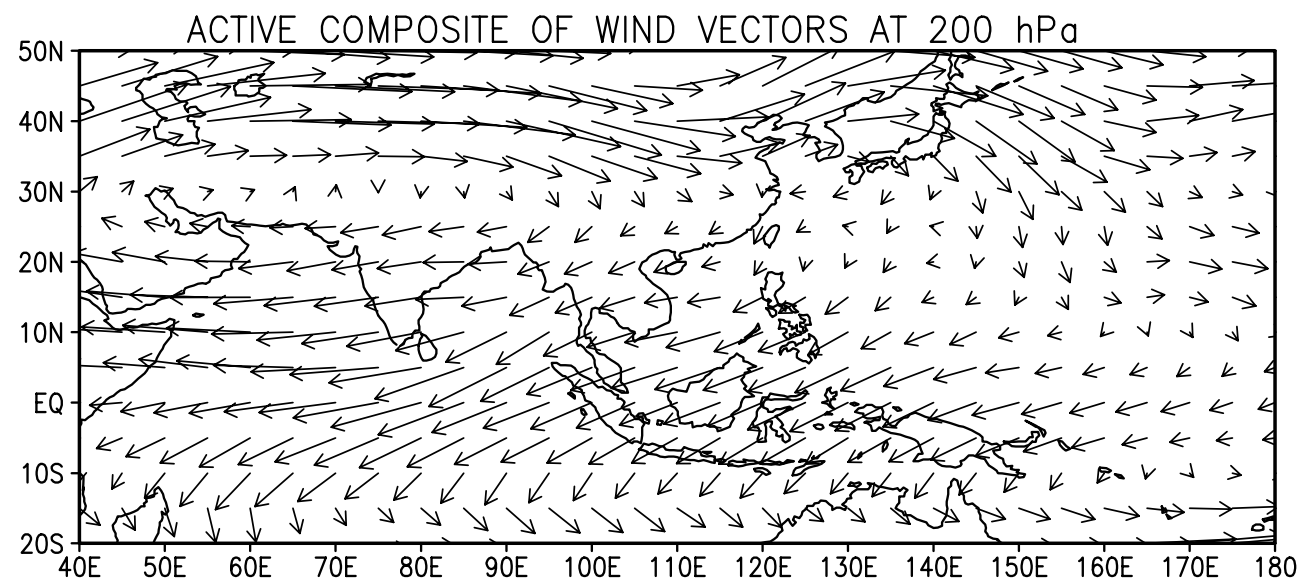

$\overrightarrow{10}$

Figure 13(c). $200 \mathrm{hpa}$ wind vectors: break composite (top), active composite (bottom).

seasons with poor rainfall. Such breaks have distinct circulation characteristics (heat trough type circulation) and have a large impact on rainfed agriculture. Although interruption of the monsoon rainfall is considered to be the most important feature of the break monsoon, traditionally, breaks have been identified on the basis of the surface pressure and wind patterns over the Indian region (Ramamurthy 1969, De et al 1998). We believe that it is useful to define breaks in terms of the rainfall distribution rather than the associated pressure and circulation characteristics. Rainfall distribution has been the basis of studies of interannual variation of the monsoon for a long time. Using rainfall/convection criteria for identifying different phases of intraseasonal variation also would be useful for investigations of teleconnections with satellite derived convection. In fact in several recent studies (e.g., Rodwell 1997; Krishnan et al 2000 and; Annamalai and Slingo 2001), different criteria based on rainfall or OLR have been used for identification of active, weak spells or breaks. We have proposed that breaks (and active spells) be identified on the basis of rainfall over the monsoon zone. The rainfall criteria are chosen so as to ensure a large overlap with the traditional breaks documented by Ramamurthy (1969) and De et al (1998). We have identified the rainbreaks for 190189.

We show that the all-India summer monsoon rainfall is significantly negatively correlated with the number of rainbreak days as well as break days identified by Ramamurthy (1969) and De et al (1998). However, the magnitude of the correlation coefficient $(-0.56)$ with rainbreak days is much larger than that with the latter $(-0.25)$. We have also identified active spells on the basis of rainfall over the Indian monsoon zone. We show that the all-India summer monsoon rainfall is highly correlated with the number of active days (correlation coefficient 0.47 ). Thus we may conclude that the interannual variation of the all-India summer monsoon rainfall is related to the number of days of rainbreaks and active spells identified here. 
We find that there is considerable overlap between the rainbreaks we have identified and breaks based on the traditional definition. There is some overlap with the breaks identified by Krishnan et al (2000) but little overlap with breaks identified by Webster et al (1998). We have derived the OLR and circulation patterns associated with rainbreaks and active spells and compared them with the patterns associated with breaks/active minus break spells with that of Webster et al (1998); Krishnan et al (2000); Goswami and Mohan (2000); and Annamalai and Slingo (2001). There are differences in the OLR/precipitation anomaly patterns associated with the breaks based on different criteria over the Indian region. For example the maximum anomaly in the $\mathrm{W}$ active minus break pattern occurs around $10^{\circ} \mathrm{N}$, that for GM breaks is over the head Bay of Bengal, that for $\mathrm{K}$ breaks and AS active minus break pattern as well as rainbreaks is over the Indian monsoon zone. There are differences in the patterns of variation over the monsoon zone, associated with the $\mathrm{K}$ breaks and the AS active minus breaks and rainbreaks. The magnitude of the maximum anomaly is larger for rainbreaks. Further, there are three or four active-break cycles in a season according to Webster et al (1998) which implies a time scale of about 40 days for which AS and GM have studied active minus break fluctuations. On the other hand, neither the traditional breaks (R-breaks, D-breaks) nor the rainbreaks occur every year. This suggests that the 'breaks' in these studies are weak spells of the intraseasonal variation of the monsoon, which occur every year.

Inspite of the differences in the patterns over the Indian region, there is one feature which is seen in the OLR anomaly patterns of breaks identified on the basis of different criteria as well as the rainbreaks identified in this paper viz., a quadrapole over the Asia west Pacific region arising from anomalies opposite (same) in sign to those over the Indian region occurring over the equatorial Indian Ocean and northern tropical (equatorial) parts of the west Pacific. Thus it appears that this quadrapole is a basic feature of weak spells of the intraseasonal variation over the Asia-west Pacific region. Since the rainbreaks are intense weak spells, this basic feature is also seen in the composite patterns of these breaks. However, it is not a distinguishing attribute of such breaks. We find that rainbreaks (active spells) are also associated with negative (positive) anomalies over a part of the east Pacific suggesting that the convection over the Indian region is linked to that over the east Pacific not only on interannual scale (as evinced by the link between the Indian summer monsoon rainfall and ENSO) but on the intraseasonal scale as well.
Clearly, a realistic simulation of this basic feature of weak spells by a model is a prerequisite for using the model for understanding the intraseasonal variation over the Asia-W. Pacific region. However, for understanding the phenomenon of breaks in the monsoon studied for several decades, or rainbreaks, the model must also simulate realistically the rainfall anomaly pattern over the Indian region, associated with these breaks. Studies with such models and analysis of observations are required to elucidate the cause-effect relationships of the links with convection over the equatorial Indian Ocean and the west and east Pacific Ocean and also the relationship of the anomalies of convection over these oceanic regions to the SST field.

\section{Acknowledgements}

The work presented here began as a collaboration between us and Ms. Asha Guruprasad, a valued colleague who passed away suddenly in 1998. We thank Savitri Bhat, Mahesh and Pulla Reddy for help in preparation of the paper and colleagues at the Centre for Atmospheric and Oceanic Sciences for stimulating discussions. The detailed comments of reviewers and the financial support by the Indian Space Research Organization is gratefully acknowledged.

\section{References}

Alexander G, Keshavamurty R N, De U S, Chellappa R, Das S K and Pillai P V 1978 Fluctuations of monsoon activity; Indian J. Meteor. Geophys. 29 76-87

Annamalai H and Slingo J M 2001 Active/break cycles: diagnosis of the intraseasonal variability of the Asian Summer Monsoon; Climate Dynamics 18 85-102

Blanford H F 1886 Rainfall of India; Mem. Ind. Met. Dept. $2217-448$

Cadet K L and Daniel P 1988 Long-range forecast of the break and active summer monsoons; Tellus 40A 133-150

De U S, Lele R R and Natu J C 1998 Breaks in southwest monsoon; India Meteorological Department, Report No. $1998 / 3$

De U S and Mukhopadhyay R K 2002 Breaks in monsoon and related precursors; Mausam 53 309-318

Dhar O N, Rakhecha P R and Mandal B N 1980 Is the number of cyclonic disturbance traversing India during the monsoon season related to the rainfall in that season?, Mausam 31 119-124

Eliot J 1884 Account of southwest monsoon storms generated in the Bay of Bengal during 1877-1881; Mem. Ind. Met. Dept. 2 217-448

Findlater J 1969 A major low level air current near the Indian Ocean during the northern summer; $Q$. J. Roy. Met. Soc. 95 362-380.

Gadgil Sulochana and Asha G 1992 Intraseasonal variation of the Indian summer monsoon 1: Observational aspects; Jap. Met. Society $\mathbf{7 0} 517-527$

Gadgil Sulochana, Sajani Surendran 1998 Monsoon Precipitation in the AMIP runs; Climate Dynamics 14 659-89 
Goswami B N and Mohan R S A 2000 Intraseasonal oscillations and interannual variability of the Indian summer monsoon; J. Climate 14 1180-1198

Gruber A and Krueger A 1984 The status of the NOAA outgoing longwave radiation data set; Bull. Amer. Meteor. Soc. 65 958-962

IMD 1888 Indian Daily Weather Report, India Meteorological Department, New Delhi.

Joseph P V and Srinivasan J 1999 Rossby waves in May and the Indian summer monsoon rainfall; Tellus 51A 854-864

Joseph P V and Raman P L 1966 Existence of low level westerly jet streams over peninsular India during July; Indian J. Met. Geophys $\mathbf{1 7}$ 407-410

Kalnay E and Coauthors 1996 The NCEP/NCAR 40-Year Reanalysis Project; Bull. Amer. Meteor. Soc. 77 437-471

Koteswaram P 1950 Upper air lows in low latitudes in the Indian area during southwest monsoon season and "Breaks" in the monsoon; ibid 1 No. 2, 162-164

Krishnan R, Zhang C and Sugi M 2000 Dynamics of breaks in the Indian summer monsoon; J. Atmos. Sci. 579 13541372

Krishnamurti T N and Bhalme H N 1976 Oscillations of a monsoon system. Part 1 . Observational aspects; $J$. Atmos. Sci. 33 1937-1954

Lucas L E, Waliser D E, Xie P, Jaonwiak J E and Liebmann B 2000 Estimating the satellite equatorial crossing time biases in the daily, global outgoing longwave radiation dataset, submission to journal of climate.

Magana V and Webster P J 1996 Atmospheric circulations during active and break periods of the Asian monsoon; Preprints of the Eighth Conference on the Global Ocean-Atmosphere-Land System (GOALS); Amer. Meteorol. Soc. Atlanta, GA.

Malurkar S L 1950 Notes on analysis of weather of India and neighbourhood; Memoirs of 1. Met. D. XXVII Part IV 139-215

Mukherjee A K and Natarajan G 1968 "Westward moving sea level low pressure systems in the south Bay of Bengal during southwest monsoon" I.J.M.G. 19(3) 284-288

Murakami T 1976 Cloudiness fluctuations during the summer monsoon; J. Met. Soc. Japan 54 175-181

Normand C 1953 Monsoon seasonal forecasting; Q. J. Roy. Meteorol. Soc. $79463-473$

Parthasarathy B, Munot A A and Kothawale D R 1994 All India monthly and seasonal rainfall series: 1871-1993. Theor. Appl. Climatol. 49 217-224

Pisharoty P R and Asnani G C 1957 Rainfall around monsoon depressions over India; Indian J. Met. Geophys. 8 15-20

Pisharoty P R and Desai B N 1956 "Western disturbances and Indian weather"; Indian Journ. Met. and Geophys. VII $333-338$
Raghavan K 1973 Break monsoon over India; Mon. Weather Rev $10133-43$

Ramaswamy C 1962 "Breaks in the Indian summer monsoon as a phenomenon of interaction between the easterly and subtropical westerly jet streams"; Tellus XIV No. 3, 337349

Rao Y P 1976 Southwest monsoon India Meteorological Department; Meteorological Monograph Synoptic Meteorology, No. 1/1976, Delhi, 367 pp.

Ramamurthy K 1969 Monsoon of India: Some aspects of the 'break' in the Indian southwest monsoon during July and August. Forecasting Manual 1-57 No. IV 18.3; India Met. Dept., Poona, India.

Rodwell M J 1997 Breaks in the asian monsoon: the influence of Southern Hemisphere weather systems; J. Atmos. Sci. 54 2597-2611

Sikka D R 1977 Some aspects of the life history, structure and movement of monsoon depressions, Vol. 115, Birkhauser Verlag, Basel pp. 1501-1526

Sikka D R and Sulochana Gadgil 1978 Large-scale rainfall over India during the summer monsoon and its relation of the lower and upper tropospheric vorticity; Indian J. Meteorol. Hydrol. Geophys. 29 219-231

Sikka D R and Sulochana Gadgil 1980 On the maximum cloud zone and the ITCZ over India longitude during the southwest monsoon; Mon. Weather Rev. 108 18401853

Sikka D R 1980 Some aspects of the large-scale fluctuations of summer monsoon rainfall over India in relation to fluctuations in the planetary and regional scale circulation parameters; Proc. Indian Acad. Sci. (Earth Planet. Sci.) 89 179-195

Slingo J M et al 1996 Intraseasonal oscillations in 15 atmospheric general circulation models: results from an AMIP diagnostics subproject; Clim. Dyn 12 325357

Sperber K R and Palmer T N 1996 Interannual tropical rainfall variability in general circulation model simulations associated with the atmospheric model intercomparison project; J. Clim 6:9(11) 2727-2750

Sperber K R, Slingo J M and Annamalai H 2000 Predictability and the relationship between subseasonal and interannual variability during the Asian Summer Monsoon; $Q$. J. Roy Meteorol. Soc. 126 2545-74

Waliser D E and Zhou W 1997 Removing satellite equatorial crossing time biases from the OLR and HRC datasets; $J$. Climate 10 2125-2146

Webster P J, Magana V O, Palmer T N, Shukla J, Tomas R A, Yanai M and Yasunari T 1998 Monsoons: Processes, predictability, and the prospects for prediction; J. Geophys. Res. 103 No. C7, pp. 14,45114,510 